Bladder tissue-resident memory $T$ cells are necessary and sufficient to mediate immunity to recurrent UTI

Matthieu Rousseau $^{1}$, Livia Lacerda Mariano ${ }^{1}$, Tracy Canton $^{1}$, Molly A Ingersoll ${ }^{1 *}$

${ }^{1}$ Mucosal Inflammation and Immunity, Department of Immunology, Institut Pasteur, 75015 Paris, France and Inserm U1223, Paris France

*Corresponding author 


\begin{abstract}
Urinary tract infection (UTI) is one of the most prevalent human bacterial infections. Due to the rapid rise of multidrug-resistant uropathogens in global circulation, new therapeutic approaches, including vaccines and immunotherapy, are urgently needed. However, the development of these therapies is impeded by an incomplete understanding of how memory develops during UTI. Here, we found that reducing bacteria load early in infection, by reducing the quantity of bacteria used for infection or with antibiotics, completely abrogated the protective memory response. As we observed that a mixed Thelper cell polarization bias, comprised of Th1, Th2, and Th17 T cells, develops, we hypothesized that reducing antigen load likely altered $\mathrm{T}$ helper cell polarization. Surprisingly, $\mathrm{T}$ helper cell polarization was unchanged in these scenarios, however, we identified a population of tissue resident memory $\left(T_{R M}\right) T$ cells that was significantly reduced in the absence of sufficient antigen, supporting that this population is necessary for protection. To demonstrate that they are sufficient for memory against recurrent UTI, we depleted circulating and lymph node-resident $\mathrm{T}$ cells, and observed that mice were still protected against a second infection. Our findings uncover an unappreciated mechanism of immunity to UTI and key role for $\mathrm{T}_{\mathrm{RM}}$ cells in the memory response to bacterial infection in the bladder, providing a target for non-antibiotic-based immunotherapy and/or new vaccine strategies to improve the response to UTI.
\end{abstract}




\section{Introduction}

Urinary tract infection (UTI), caused predominantly by uropathogenic E. coli (UPEC), is one of the most prevalent human bacterial infections (Litwin et al., 2007). Women experience UTI at a significantly higher incidence than men; and children, the elderly, pregnant women, and immunocompromised individuals are at even greater risk than the general population of developing complications such as chronic infection, pyelonephritis, and subsequent kidney damage from infection (Chromek and Brauner, 2007; De Nisco et al., 2019; Dielubanza and Schaeffer, 2011; Hoepelman et al., 1992; Mazor-Dray et al., 2009). Approximately every second woman will have one UTI in her lifetime, with the highest risk between the ages of 16 and 35, when women are 35 times more likely than men to be infected (Foxman, 2002). Additionally, nearly half of all infected women will experience recurrent UTI, defined by similar or identical symptoms, within 6 months of their first infection (Ikaheimo et al., 1996). Although the incidence of infection is much lower in adult men (around 1\%), in this population, UTI is always considered a complicated infection, with considerable risk of becoming a recurrent or chronic infection (Lipsky, 1989). In addition, the prevalence of UTI increases substantially in older men, bringing with it increased morbidity and mortality in this aging population (Ruben et al., 1995).

Given the diversity of at-risk populations, the frequency of recurrence, and the considerable increase in multi-drug resistant UPEC isolates in global circulation, new therapeutic approaches, such as immune modulation, are needed to combat chronic and recurrent UTI (Klein and Hultgren, 2020; Lacerda Mariano and Ingersoll, 2020). Indeed, antibiotics only diminish acute bacterial burden, and currently, there is no treatment or therapy that protects against initial or recurrent UTI (Lacerda Mariano and Ingersoll, 2020). Although experimental vaccination in humans and mice induces antibody production that reduces bacterial colonization, these attempts have not lead to a successful clinically available vaccine (Alteri et al., 2009; Billips et al., 2009; Klein and Hultgren, 2020; Langermann et al., 1997; Uehling et al., 1997; Uehling et al., 2001; Uehling et al., 1994; Uehling et al., 1991). Recurrent UTI likely arises due to several factors, including development of reservoirs in the bladder and gut, or inadequate development of memory responses to a primary infection (Mora-Bau et al., 2015; Mysorekar and Hultgren, 2006; Spaulding et al., 2017). As the associated costs of UTI, including treatment and lost productivity, amount to more than $\$ 3$ billion in the US, with similar expenditures in Europe (Sivick and Mobley, 2009), a better understanding of how immunity arises and how it can be targeted to improve the response to UTI would have a profoundly positive societal and economic impact, as well as improve the quality of life of those suffering from recurrent infection.

Notably, however, how adaptive immunity develops in response to bladder infection is still incompletely understood (Ingersoll and Albert, 2013; Lacerda Mariano and Ingersoll, 2020). An early key observation, that mice infected with an ovalbumin-expressing UPEC strain have ovalbumin-specific antibodies in the serum and reduced bacterial burden following a second or challenge infection, demonstrated that protective memory can develop during UTI (Thumbikat et al., 2006). Using isogenic UPEC strains expressing different antibiotic resistance genes, we demonstrated that acute bacterial burden in the bladder is reduced following challenge infection compared to a first UTI (Mora-Bau et al., 2015). Bacterial burden is similar between primary and challenge infection in RAG2 ${ }^{-/}$mice, dendritic cell-depleted mice, and CD4 and CD8 T cell-depleted mice, supporting that the reduced bacterial burden observed after a challenge infection in wildtype mice is mediated by an adaptive immune or memory response (Mora-Bau et al., 2015). Together, these data support that adaptive immunity to UPEC infection does arise, however whether T cells or antibodies are the key players in bacterial clearance is unclear. A more recent study suggested that a Th2-biased T cell response develops during UTI to promote bladder epithelial repair, at the expense of bacterial clearance (Wu et al., 2020). While this is seemingly a potential explanation for why the memory response to UTI is nonsterilizing, this work fails 
to consider that while a type 2 biased immune response develops in female mice, Th2 polarization is absent in male mice (Zychlinsky Scharff et al., 2019). Importantly, despite the absence of a Th2-bias in the $\mathrm{T}$ cell response, female and male mice exhibit the same degree of nonsterilizing protection against a challenge infection (Zychlinsky Scharff et al., 2019). Additionally, the cytokine response to UTI suggests that a Th2 T cell bias is not the determinant factor in whether memory develops or how protective the response is to UTI (Mora-Bau et al., 2015; Zychlinsky Scharff et al., 2019).

Thus, to understand how a memory response arises following UTI, we investigated the kinetics and bias of the T cell response in the context of primary and recurrent UTI. We observed that a mixed Th1, Th2, and Th17 response arose during the first and second infection. Antigen persistence was necessary for immunity, as memory was abrogated after early antibiotic treatment or in the context of a smaller inoculum. Finally, we identified that a tissue resident population of $T$ cells, $T_{R M} T$ cells, were sufficient to mediate the memory response, as mice were protected during a second infection even in the absence of circulating $\mathrm{T}$ cells. These findings support that local mucosal responses, and not systemic immunity, determine memory to UTI, providing a specific target for new therapeutics.

\section{Results}

\section{CD4 or CD8 T cells are sufficient for immune memory to UTI}

C57BL/6 mice have significantly lower bacterial burdens after a second or challenge infection compared to those seen following a primary infection with UPEC (Mora-Bau et al., 2015; Zychlinsky Scharff et al., 2019). Supporting that this is due to an immune memory response, this phenotype disappears in the absence of $\mathrm{B}$ or T cells, such as in RAG2 ${ }^{-/}$mice or in CD4 and CD8-depleted C57BL/6 mice (MoraBau et al., 2015). Given that urine from women who have experienced UTI inhibits UPEC binding to human urothelial cells and that antibody depletion of this urine abrogates its inhibitory capacity (Svanborg-Eden and Svennerholm, 1978), we hypothesized that immune memory to UTI is mediated by a specific B cell response.

To test this hypothesis, we intravesically instilled 6 to 8 -week-old wildtype female C57BL/6 or $\mu \mathrm{MT}^{-/-}$ mice, which lack mature B cells (Kitamura et al., 1991), with $10^{7}$ colony forming units (CFU) of 1 of 2 isogenic UPEC strains encoding resistance to ampicillin (UTI89-GFP-amp ${ }^{\mathrm{R}}$ ) or kanamycin (UTI89RFP-kana ${ }^{\mathrm{R}}$ ). Half of the mice from each group were sacrificed 24 hours post-infection (PI) to assess the bacterial burden in the bladder. Resolution was monitored in the remaining mice by urine sampling twice per week for 4 weeks, with the sustained absence of bacteria indicating a resolved infection. At 4 weeks PI, all resolved mice were challenged with $10^{7} \mathrm{CFU}$ of the isogenic UPEC strain not used in the primary infection, to model a recurrent UTI. The presence of different antibiotic resistance markers between the first and second infection allows us to distinguish bacteria that established dormant tissue reservoirs following primary infection from those causing acute infection following challenge. We sacrificed animals 24 hours post-challenge infection to assess bacterial CFU. As expected, bacterial burden was significantly reduced 24 hours post challenge $\left(2^{\circ}\right)$ compared to levels measured following primary infection $\left(1^{\circ}\right)$ in wildtype mice. Surprisingly, a comparable, statistically significant reduction in bacterial $\mathrm{CFU}$ was also observed in $\mu \mathrm{MT}^{-/-}$mice following challenge infection compared to the primary UTI, suggesting that B cells are dispensable for protective memory to UTI (Figure 1A).

Having ruled out a role for B cells, we tested which of the two major types of $\mathrm{T}$ cells were necessary for immune memory to UTI. Six- to eight-week-old female C57BL/6 mice were treated with anti-CD4 or anti-CD8 depleting antibodies, or relevant isotype controls, and then infected three days later with $10^{7}$ CFU of 1 of the 2 isogenic UTI89 strains. Primary bacterial burden was assessed in half of the animals 
at 24 hours PI and the remaining mice were challenged with $10^{7} \mathrm{CFU}$ of the second isogenic UPEC strain following resolution of infection at 4 weeks. In the isotype control groups, bacterial burdens 24 hours after challenge infection were statistically significantly reduced compared to primary infection, as expected. Strikingly, bacterial burden was also significantly reduced in mice treated with anti-CD4 or anti-CD8 depleting antibodies (Figure 1B, C). Together, our findings support that while B cells are dispensible either CD4 or CD8 T cells are sufficient for immune memory to UTI.

A

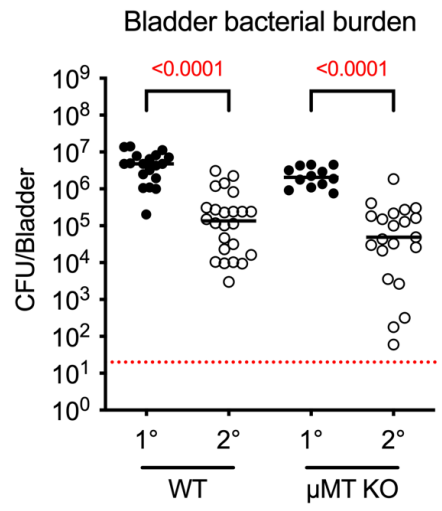

$\mathrm{B}$

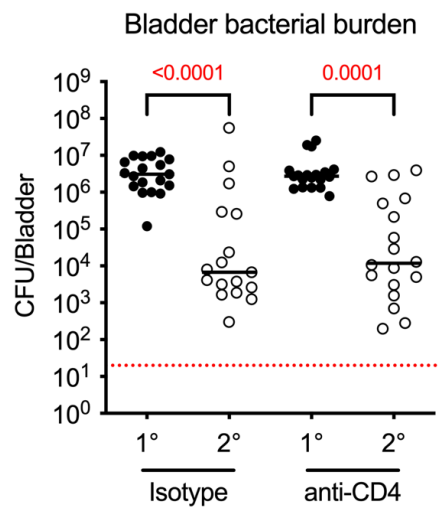

C

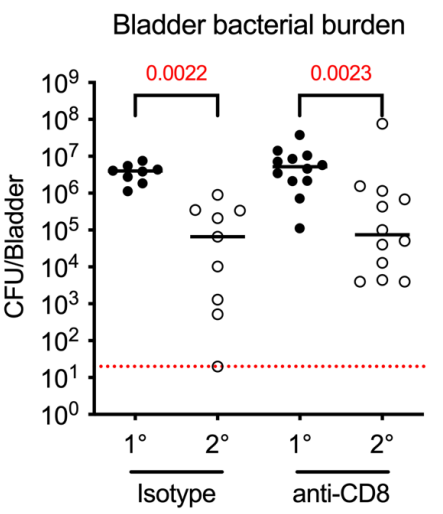

Figure 1: CD4 or CD8 T cells mediate protection against a second UTI. Six- to eight-weekold female $\mathrm{C} 57 \mathrm{BL} / 6$ or $\mu \mathrm{MT}^{-/-}$mice were instilled intravesically with $10^{7} \mathrm{CFU}$ of UPEC strain UTI89 and bladder bacterial burden was assessed 24 hours post-primary infection $\left(1^{\circ}\right.$, filled circles). Urine was monitored twice per week for 4 weeks and all resolved mice (with sterile urine) were challenged with an isogenic UTI89 strain and bacterial burden was assessed 24 hours after challenge infection ( $2^{\circ}$, open circles). Graphs depict $1^{\circ}$ and $2^{\circ} \mathrm{CFU} /$ bladder in (A) C57BL/6 or $\mu \mathrm{MT}^{-/}$mice, (B) isotype or anti-CD4 antibody-treated mice, or $(\mathbf{C})$ isotype or anti-CD8 antibody-treated mice. Data are pooled from 2-5 experiments, $n=2$ to 7 mice/group in each experiment. Each dot represents a mouse, lines are medians. Dotted red lines depict the limit of detection of the assay, $20 \mathrm{CFU} /$ bladder. Significance (adjusted $p$-value) was determined using a Kruskal-Wallis test comparing bacterial burden 24 hours post $1^{\circ}$ to $2^{\circ}$ within a treatment group, with a Dunn's post hoc test to correct for multiple comparisons. $p$-values $<0.05$ are in red.

\section{$T$ cell polarization is mixed during primary and challenge UTI}

Having determined that $\mathrm{T}$ cells are sufficient for immune protection, we assessed the $\mathrm{T}$ cell bias arising during infection. While it was proposed that a type 2 immune response leads to suboptimal memory to UTI in mice (Wu et al., 2020), we reported that female and male mice develop similar non-sterilizing adaptive immunity to UTI despite that cytokine responses and immune cell infiltration are starkly different between the sexes (Zychlinsky Scharff et al., 2019). Notably, only female mice express type 2 cytokines during acute infection (Mora-Bau et al., 2015; Zychlinsky Scharff et al., 2019). Thus, we hypothesized that other mechanisms are at play in shaping the adaptive response to UTI.

To test this, we determined the polarization of bladder-infiltrating CD4 T cells over time after primary and challenge infection. We focused on CD4 T cells because CD4 T cell infiltration is greater than 100 times higher than CD8 T cell infiltration following infection of naïve mice (Supplementary Figure 1). Six-week-old female C57BL/6 mice were sacrificed at day 1, 3, and 7 post primary and challenge UPEC infection. Using intracellular staining and flow cytometry, we determined $\mathrm{T}$ cell polarization using transcription factor and cytokine expression (T-bet ${ }^{+}$, IFN $\gamma$ : Th1; Gata-3 $3^{+}$IL-4: Th2; ROR $\gamma \mathrm{T}^{+}$, IL-17: Th17). Compared to naïve animals (day 0), total CD4 $\mathrm{T}$ cells increased approximately 10 -fold in the 
bladder over time after primary infection (Figure 2A). A similar increase was seen between mice 7 days after the challenge UTI compared to resolved mice before they were given a challenge infection (R), although the baseline in the resolved animals was significantly higher than in naïve mice (Figure 2A). Instead of a distinct polarization program, a mixed bias was clearly apparent among infiltrating CD4 T cells following primary and challenge UTI (Figure 2A). Of the global CD4 T cell population expressing one of these three transcription factors, T-bet ${ }^{+}$Th1 T cells made up $\sim 10-20 \%$ of cells, Gata- $3^{+}$Th2polarized $\mathrm{T}$ cells represented $\sim 5-15 \%$ of cells, and ROR $\mathrm{t}^{+} \mathrm{Th} 17 \mathrm{~T}$ cells made up $\sim 3-30 \%$ of cells over time in the primary and challenge infections (Figure 2B). Strikingly, no T helper cell subset dominated the response, and indeed, only one mouse in all experiments performed had more than 50\% Th2-biased $\mathrm{T}$ cells in a single timepoint. Furthermore, while the numbers of IFN $\gamma^{+}$Th1 T cells and IL- $17^{+} \mathrm{Th} 17 \mathrm{~T}$ cells were significantly increased after primary infection, we detected no IL-4-expressing Th2-biased T cells, in line with our previous results that IL-4 levels are 10-100 times lower than any other cytokine measured (Zychlinsky Scharff et al., 2019). These data support that a dominant Th2 bias does not develop during UTI (Figure 2C). In addition to Th1, Th2, and Th17 T cells, a large number of FoxP3 ${ }^{+}$ regulatory T cells (Tregs) infiltrated the bladder after primary UTI, remained elevated compared to naïve levels after challenge infection, and made up $10-30 \%$ of total CD4 T cells over time (Figure 2D). Interestingly, all CD4 Th cell subsets increased substantially during the first UTI and remained significantly elevated over naïve levels in resolved mice, supporting that the bladder is imprinted for at least one month after a first UTI.

We observed a similar mixed bias among $\mathrm{T}$ cells in the draining lymph nodes after both infections and increased numbers of IFN $\gamma^{+}$Th1 T cells, IL- $17^{+}$Th17 T cells, and CD4 Tregs (Figure 2E, F, and G, respectively). Th2, Th17, IFN $\gamma^{+}$Th1, and IL-17 ${ }^{+}$Th17 T cells were increased in lymph nodes in resolved mice compared to naïve animals, supporting that the draining lymph nodes are also imprinted at least a month after a primary infection. 
A
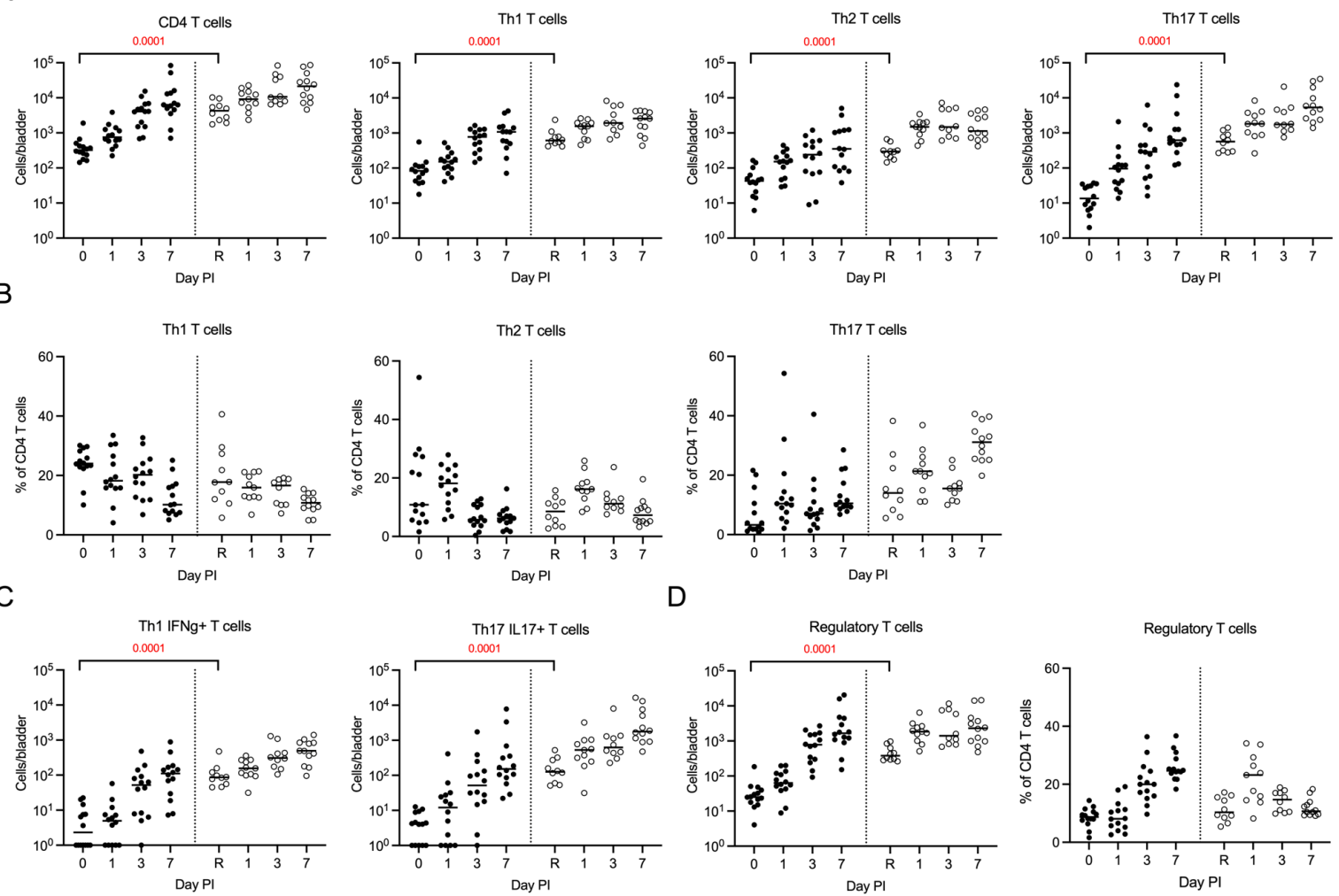

$\mathrm{E}$
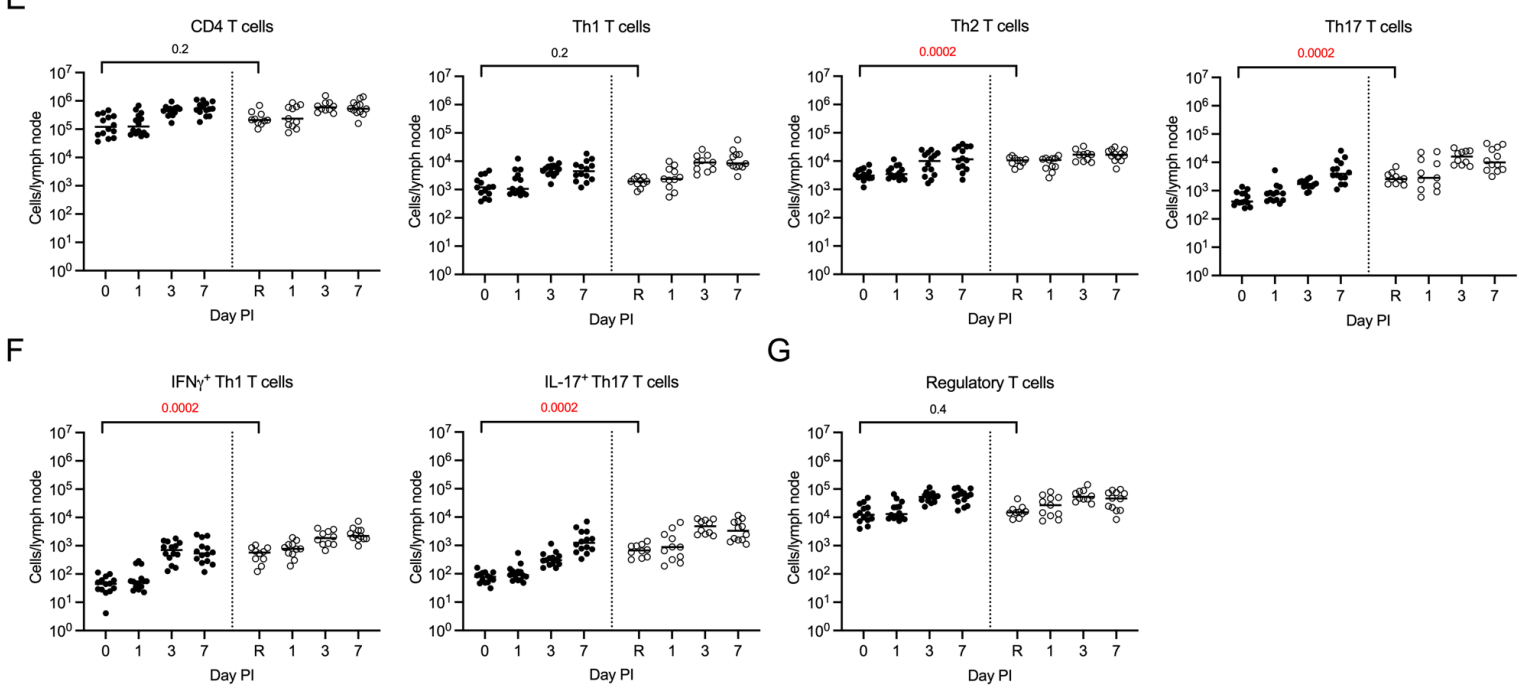

Figure 2: No distinct CD4 Th T cell bias is apparent during primary and recurrent UTI. Six-week-old infected female C57BL/6 mice were sacrificed at the indicated timepoints postprimary (filled circles), or post-challenge infection (open circles). Day 0 are naïve mice and ' $R$ ' denotes animals that resolved their primary UTI but were not challenged with a second infection. The graphs depict (A) total CD4, Th1, Th2, and Th17 T cells, (B) percentage of the global CD4 $\mathrm{T}$ cell population for the indicated Th subset, (C) total IFN $\gamma^{+} \mathrm{Th} 1$ and IL- $17^{+} \mathrm{Th} 17 \mathrm{~T}$ cells, and (D) total Tregs and percentage of Tregs among total CD4 T cells in the bladder at the indicated day post primary or challenge infection. The graphs depict total (E) CD4, Th1, Th2, or Th17 T cells, (F) IFN $\gamma^{+}$Th1 or IL-17 $7^{+}$Th17 T cells, and (G) Tregs, in the draining lymph nodes at the indicated day post primary or challenge infection. Data are pooled from 2 experiments, $n=5$ to 7 
mice/group in each experiment. Each point is a mouse and lines are medians. Nonparametric Mann-Whitney tests comparing cell numbers between ' 0 ' and ' $\mathrm{R}$ ' were performed. All $p$-values were corrected for multiple comparisons across all populations shown using the false discovery rate (FDR) method and $p$-values $<0.05$ are in red.

\section{Regulatory T cells outnumber CD4 T helper cells}

The cellular response in the bladder and lymph nodes included a large number of Treg T cells. A balanced Treg/Th $\mathrm{T}$ cell ratio is important to maintain immune tolerance, but also to have an efficient immune response against pathogens (Falivene et al., 2015; Yordanova et al., 2019). A skewed ratio, in which Tregs are outnumbered by Th cell subsets is often observed in autoimmune diseases and leads to uncontrolled inflammation and tissue damage, whereas a higher ratio of Tregs to Th cell subsets is detrimental in cancer as the suppressive environment impedes tumor killing by cytotoxic $\mathrm{T}$ cells (Baras et al., 2016; Ji et al., 2012; Preston et al., 2013; Xu et al., 2017; Yang et al., 2009). Thus, we calculated the ratio of Tregs to all CD4 Th cells in the bladder and draining lymph nodes. In the bladder, we found that, globally, the ratio of Tregs to Th cells was under or near 1 for all timepoints measured (Figure 3A). However, the ratio far exceeded 1 in the lymph nodes during primary UTI and was near 1 during the second infection (Figure 3B). When we considered the ratio of Tregs to Th1, Th2, or Th17 T cells individually, we observed that generally it was at or below 1 in naïve mice (Day 0 ) and mice infected for 24 hours, however, the ratios increased over 1 at day 3 and 7 post-primary infection, and remained near 1 during the second infection (Figure 3C). The Treg to each Th subset ratio was striking increased over 1 in the lymph nodes (medians ranging from 3.5 to 32) over time, however this was more pronounced during the primary infection compared to the second UTI (Figure 3D). Thus, Treg T cells are highly prevalent during UTI, and given their abundance in the lymph node, and later in the bladder, may act to suppress the development of memory $\mathrm{T}$ cells, particularly after a first infection.

A

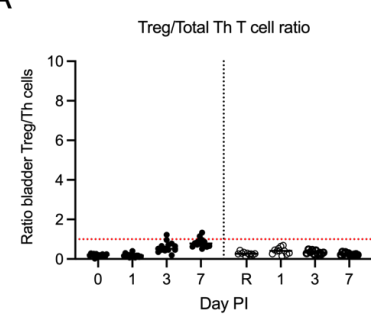

C

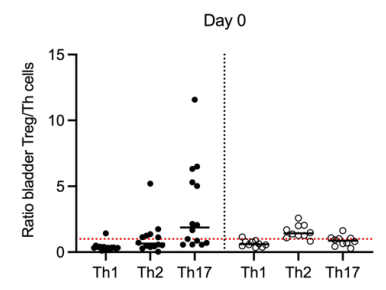

D

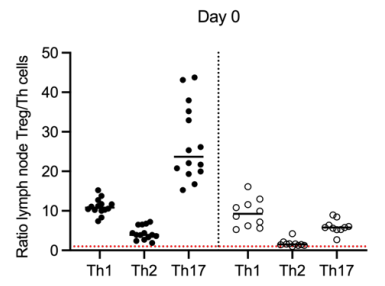

B

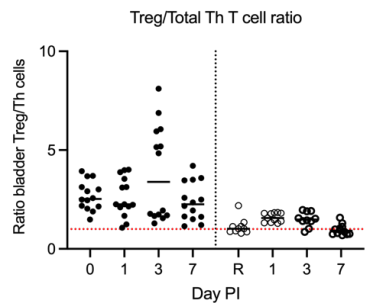

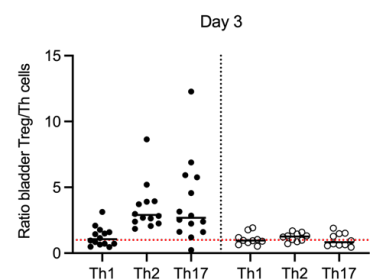

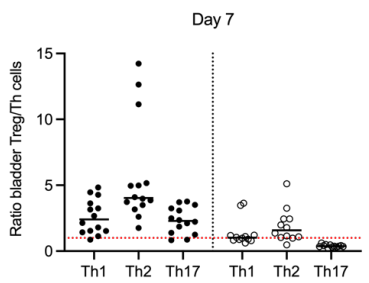

Figure 3: Regulatory $\mathbf{T}$ cells outnumber Th cell subsets in the lymph nodes. The Treg/Th cell ratios for the indicated days post-primary (filled circles), or post-challenge infection (open circles) were calculated using the cell numbers presented in Figure 2. (A) Ratio of Treg/total CD4 Th 
cell in the bladder. (B) Ratio of Treg/total CD4 Th cell in the draining lymph nodes. (C) Ratio of Treg/indicated CD4 Th cell subset in the bladder. (D) Ratio of Treg/indicated CD4 Th cell subset in the draining lymph nodes. Day 0 are naïve mice and ' $R$ ' denotes animals that resolved their primary UTI but were not challenged with a second infection. Data are pooled from 2 experiments, $\mathrm{n}=5$ to 7 mice/group in each experiment. Each dot represents a mouse and lines are medians. Dotted red lines are at 1.

\section{Antigen persistence determines the development of adaptive immunity during UTI}

Tregs outnumbered Th cell subsets in the bladder and lymph nodes, potentially inducing a suppressive or tolerant environment in response to UTI. As tolerance can be induced following suboptimal (too much or too little) antigen stimulation (Xiao and Link, 1997; Yoshida et al., 1997), we hypothesized that abundant Treg infiltration reflected the antigen quantity provided by the initial bacterial inoculum. We reported that increasing the inoculum from $10^{7} \mathrm{CFU} /$ mouse to $10^{8}$ or $10^{9} \mathrm{CFU} /$ mouse does not promote a stronger memory response to a second UTI, suggesting that our infection protocol, using a $10^{7} \mathrm{CFU} /$ mouse inoculum, likely provides sufficient antigen (Mora-Bau et al., 2015). Thus, we tested whether decreasing the inoculum, to reduce antigen load would induce a more robust memory response. We intravesically infected female C57BL/6 mice with $10^{7}, 10^{5}$, or $10^{3} \mathrm{CFU}$ of UPEC. One cohort of mice from each group was sacrificed 24 hours post-primary infection to assess bladder bacterial burden and a second cohort was monitored for resolution over 4 weeks. All resolved animals were challenged 28 days later with $10^{7} \mathrm{CFU}$ of the isogenic UPEC strain and we assessed CFU in the bladder 24 hours post-challenge infection. Mice infected with $10^{5}$ or $10^{3} \mathrm{CFU}$ resolved their primary infection faster than those infected with $10^{7} \mathrm{CFU}$ (Figure 4A). Notably, compared to the control scenario using an inoculum of $10^{7} \mathrm{CFU}$, mice infected with $10^{5}$ or $10^{3} \mathrm{CFU}$ for the primary infection were no longer protected against a challenge infection, and had higher bladder-associated bacterial burdens after their second UTI compared to the control group (Figure 4B). Notably, mice infected with $10^{3} \mathrm{CFU}$ for their primary infection had markedly reduced primary bacterial burdens near or at the limit of detection of the assay and bacterial burdens closely resembling those seen after infection of naïve mice after a challenge infection, supporting that this low-level exposure to UPEC could not induce immune memory to the bacteria.

From these data, we concluded that either initial bacterial antigen load or antigen persistence was necessary for immune memory to UTI. To create a scenario in which antigen load is the same, but antigen persistence is reduced, we infected mice with the same inoculum and treated then with antibiotics at specific days PI. The advantage of this approach is that antibiotics are the standard therapy to treat UTI, and thus, we would be modeling a clinical scenario. UPEC-infected female C57BL/6 mice were given trimethoprim/sulfamethoxazole, an antibiotic combination commonly prescribed for UTI, in the drinking water for 5 days starting at days 1, 2, 3, or 5 PI. All animals with sterile urine after 28 days were challenged with an isogenic UTI89 strain and bacterial burdens at 24 hours post-challenge infection were compared to bladder-associated CFU at 24 hours post-primary infection. We observed that when antibiotics were given at day 1 post-primary infection, the adaptive immune response was abrogated, whereas when treatment was delayed until day 2, 3, or 5 post-primary infection, bacterial burdens were significantly reduced in challenge infection, similar to that observed in the control no antibiotic treatment group (Figure 4C). Together, our findings support that antigen persistence is necessary for the development of memory in UTI. Additionally, they raise the question as to whether a previous UTI is actually a risk factor for recurrent infection (Hooton et al., 1996), or that instead, it is early antibiotic treatment that may contribute to an individual's risk for future infections due to poor immunity. 
A

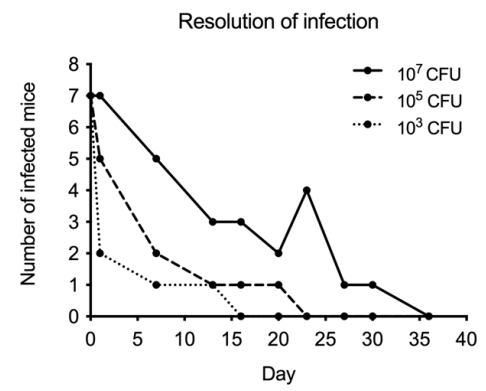

B

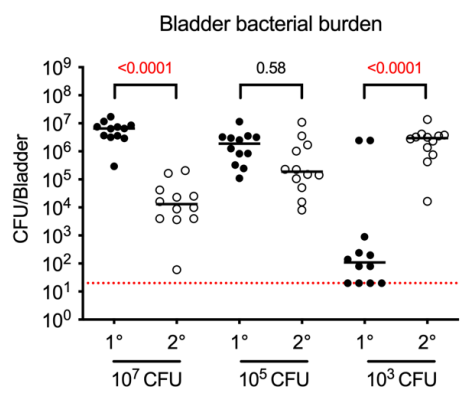

C

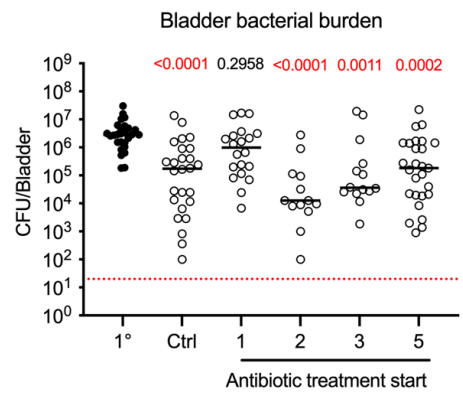

Figure 4: Antigen persistence is necessary for immune memory to UTI. 6 to 8-week-old female C57BL/6 mice were infected with $10^{7}$ (solid line), $10^{5}$ (dashed line), or $10^{3} \mathrm{CFU}$ (dotted line) of UPEC isolates UTI89-GFP-amp ${ }^{\mathrm{R}}$ or UTI89-RFP-kan ${ }^{\mathrm{R}}$. Mice were sacrificed 24 hours post-primary $\left(1^{\circ}\right.$, filled circles) or post-challenge infection $\left(2^{\circ}\right.$, open circles) for CFU assessment. (A) Resolution after primary infection was monitored twice per week by assessing the presence of UPEC in the urine. The graph depicts the number of infected mice over time and an increase in the number of infected mice is due to a spontaneous recurrent UTI. The graphs show bladder bacterial burdens following (B) primary infection with the indicated inocula and challenge infection with $10^{7}$ CFU UPEC and (C) challenge infection in mice treated with trimethoprim/sulfamethoxazole at day 1, 2, 3, or 5 post-primary infection. The control (Ctrl) group did not receive antibiotics. A depicts representative data from 1 experiment of 2 ( $\mathrm{n}=7$ mice/group). Data in $\mathbf{B}$ are pooled from 2 experiments, $\mathrm{n}=5$ to 7 mice/group in each experiment. Data in $\mathbf{C}$ are pooled from 2-4 experiments, $n=6$ to 7 mice/group in each experiment. Each point is a mouse and lines are medians. Dotted red lines depict the limit of detection of the assay, 20 CFU/bladder. In $\mathbf{B}$, significance was determined by Kruskal-Wallis test comparing bacterial burden 24 hours post $1^{\circ}$ to $2^{\circ}$ within each inoculum group and in $\mathbf{C}$, each $2^{\circ}$ group was compared to the $1^{\circ} \mathrm{CFU}$, with Dunn's post hoc test to correct for multiple comparisons performed and adjusted $p$-values for each comparison presented for both. $p$-values $<0.05$ are in red.

\section{Reduced antigen persistence does not impact Th cell polarization}

When antigen load was reduced, by decreasing the inoculum or giving antibiotics on day 1 PI, protection against a second infection was lost. We hypothesized this was due to a change in Th cell polarization proportions, impacting the memory response, as previously we reported that depletion of tissue resident macrophages, prior to a challenge infection, results in increased infiltration of type 1 effector cells, including Th1 T cells, and improved bacterial clearance (Lacerda Mariano 2020). To test this hypothesis, we infected mice with $10^{7}$ or $10^{3} \mathrm{CFU}$ of UTI89 or we infected a second cohort with $10^{7} \mathrm{CFU}$ of UTI89 and treated half of these mice with antibiotics at day 1 PI. 28 days later, we challenged all resolved mice with $10^{7} \mathrm{CFU}$ of UTI89 and sacrificed them 24 hours post-challenge to assess CD4 T cell polarization. In mice infected with $10^{3} \mathrm{CFU}$ for their first UTI, we observed a significant reduction of Th1, Th2, and Th17 $\mathrm{T}$ cell subsets, as well as decreases in IFN $\gamma^{+} \mathrm{Th} 1 \mathrm{~T}$ cells, IL-17 ${ }^{+} \mathrm{Th} 17 \mathrm{~T}$ cells, and Tregs compared to the control group (Figure 5A). Refuting our hypothesis, however, there were no differences in the proportions of each Th cell subset between mice infected with $10^{7} \mathrm{CFU}$ or $10^{3} \mathrm{CFU}$ (Figure 5B). Indeed, all Th cell subsets and Tregs decreased similarly, and as such, the frequency of each subset and therefore, the global polarization bias was the same between the groups. When we considered Th cell polarization in antibiotic-treated mice, again we observed that the proportions of each Th cell subset were unchanged compared to the control condition (Figure 5C). In contrast, though, to the decreasing inoculum experiment in Figure 5A, we did not observe a reduction in the numbers of Th1, Th2, or Th17 T cell subsets; IFN $\gamma^{+}$Th1 T cells or IL-17 $7^{+}$Th17 T cells; or Tregs between groups of mice that were antibiotic- 
treated or not (Figure 5D). Analysis of the draining lymph nodes mirrored these findings, as we observed no differences among any of the experimental groups compared to the control conditions for any of the parameters measured (Supplementary Figure 2). Notably, although both experimental groups had abrogated immune memory (Figure 4), in one scenario, $\mathrm{T}$ cell infiltration was globally reduced (Figure 5A), whereas in the second scenario, $\mathrm{T}$ cell infiltration was similar to the control group (Figure 5D). That there was no change in Th cell bias or, in the case of antibiotic treatment, a reduction in the number of Th cell subsets present suggests that the polarization and quantity of infiltrating $\mathrm{T}$ cells in response to UTI are not major determinants of whether memory will develop to UTI.

A
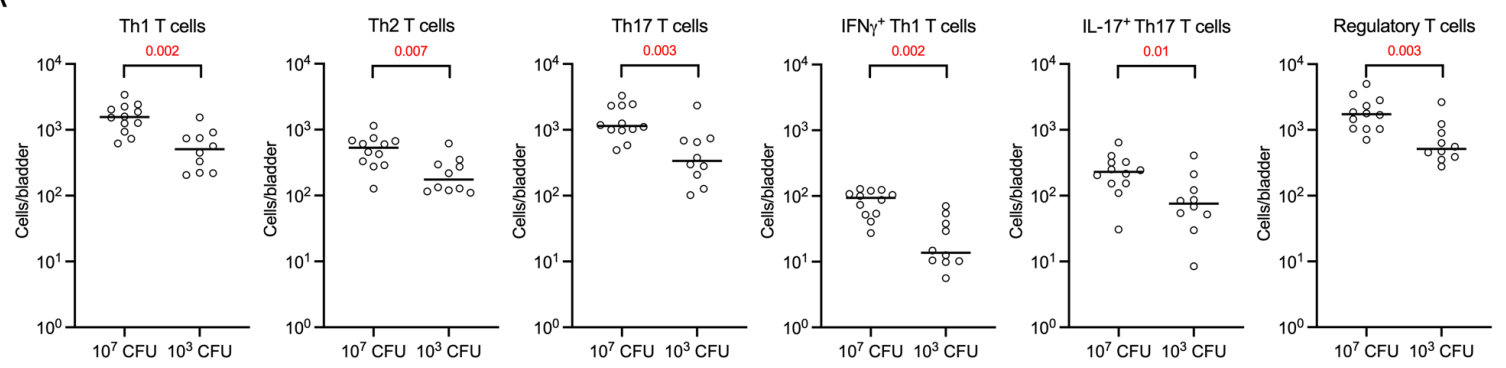

B

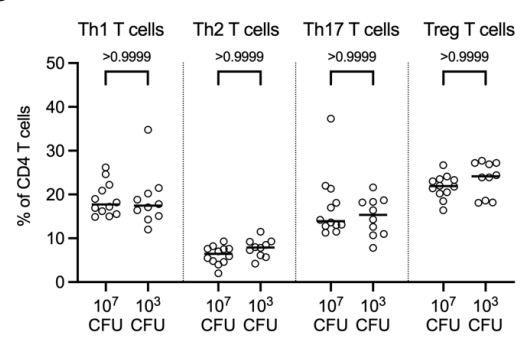

C
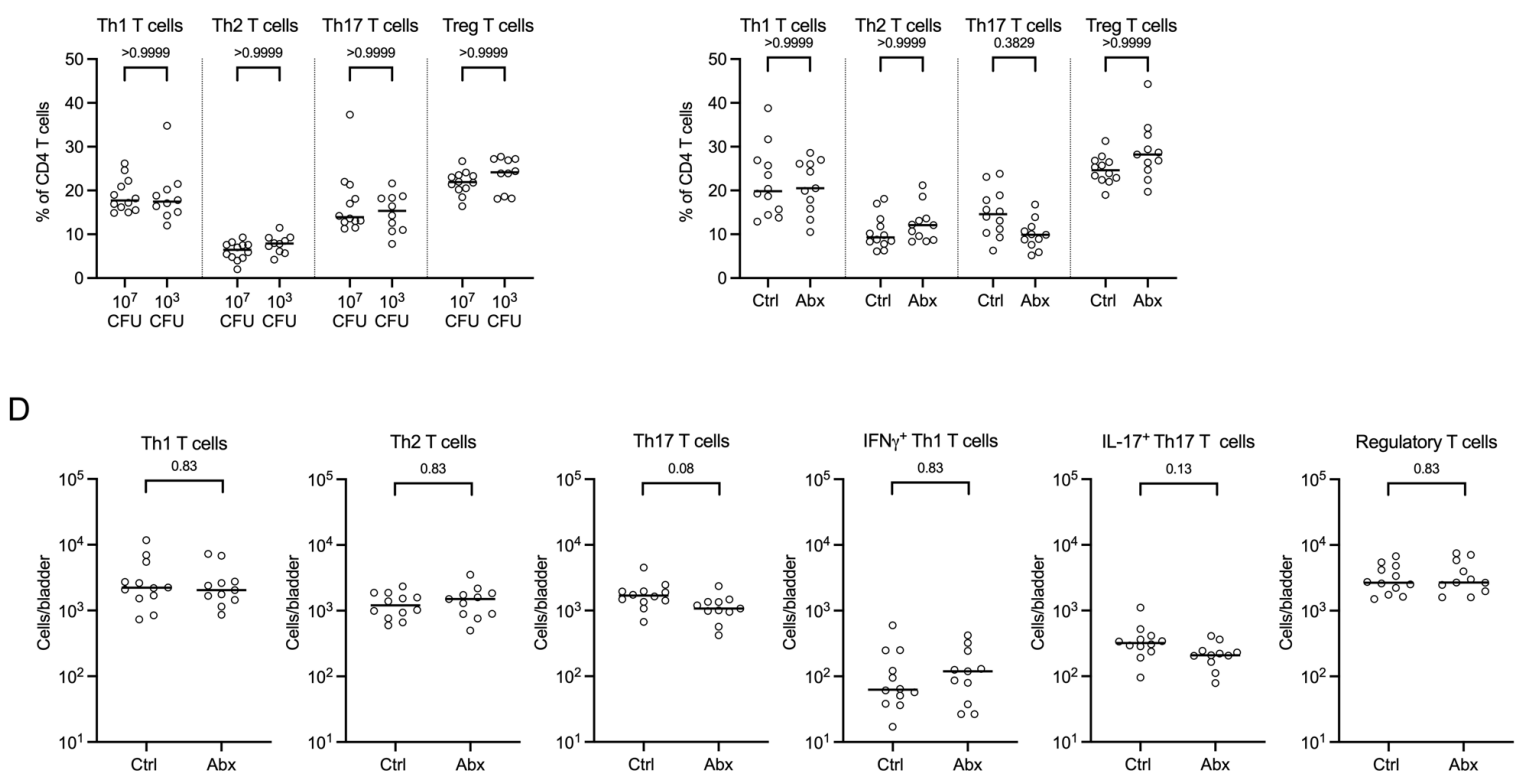

Figure 5: Th $\mathbf{T}$ cell polarization is unchanged when antigen persistence is altered. (A-B) Sixweek-old female C57BL/6 mice were intravesically infected with either $10^{7}$ or $10^{3}$ CFU of UTI89, and at day 28 resolved mice were challenged with $10^{7} \mathrm{CFU}$ of UTI89, sacrificed 24 hours postchallenge infection and bladders analyzed by flow cytometry. Graphs depict (A) the total number of the specified Th cell populations per bladder and (B) the frequency among CD4 T cells of the Th cell subsets in A. (C-D) Six-week-old female C57BL/6 mice were infected with $10^{7} \mathrm{CFU}$ of UTI89. One cohort of mice was treated 24 hours PI with antibiotics, and all resolved mice were challenged with $10^{7} \mathrm{CFU}$ of UTI89 28 days later. Bladders were analyzed by flow cytometry 24 hours post-challenge infection. Graphs show $(\mathbf{C})$ the frequency of each Th cell subset among CD4 $T$ cells and (D) the total number of the specified Th cell populations per bladder. Data are pooled from 2 experiments, $n=4$ to 6 mice/group in each experiment. Each dot represents a mouse and lines are medians. In $\mathbf{A}$ and $\mathbf{D}$, nonparametric Mann-Whitney tests comparing cell numbers between each condition were performed and all $p$-values were corrected for multiple comparisons among the same experiment using the false discovery rate (FDR) method. In $\mathbf{B}$ and $\mathbf{C}$, significance was determined by Kruskal-Wallis tests comparing the frequency of indicated $\mathrm{T}$ cell subsets for 
each condition with Dunn's post hoc test to correct for multiple comparisons were performed. $p$ values $<0.05$ are in red.

\section{Tissue resident memory $T$ cells are sufficient to mediate immune memory to recurrent UTI}

We were surprised to observe that despite comparable Th cell polarization patterns, and in the case of antibiotic treatment, the same number of infiltrating $\mathrm{T}$ cells, reducing the inoculum or using antibiotics early in infection abrogated immune memory to UPEC. To understand this unexpected result, we considered that immunological memory can be mediated through B cells (Akkaya et al., 2020), circulating central memory $\left(\mathrm{T}_{\mathrm{CM}}\right)$ and effector memory $\mathrm{T}$ cells $\left(\mathrm{T}_{\mathrm{EM}}\right)$, or a subset of long-lived stationary T cells called tissue resident memory $T$ cells $\left(T_{R M}\right)$ (Mueller et al., 2013). Our prior work, as well as our findings in Figure 1, ruled out a role for B cells, and demonstrated T cells are necessary for an adaptive response (Mora-Bau et al., 2015). The memory response to UTI, mediated by T cells, is rapid as a 2-log reduction in bacterial burden is observed in the bladder as early as 24 hours post challenge infection (Lacerda Mariano et al., 2020; Mora-Bau et al., 2015; Zychlinsky Scharff et al., 2017). Given the speed of the response, we hypothesized that $\mathrm{T}_{\mathrm{RM}}$ cells mediate immune protection. Indeed, $\mathrm{T}_{\mathrm{RM}}$ cells are found in different mucosa including the lung, intestine, and vagina, and are anatomically positioned for immediate detection and response to pathogens to provide localized immunological memory and more rapid protection against pathogen re-infection compared to $\mathrm{T}_{\mathrm{CM}}$ or $\mathrm{T}_{\mathrm{EM}}$ cells (Gebhardt et al., 2009; Iijima and Iwasaki, 2014; Jiang et al., 2012; Perdomo et al., 2016; Romagnoli et al., 2017; Schenkel et al., 2013; Shin and Iwasaki, 2012; Teijaro et al., 2011).

To test this hypothesis, we infected mice with $10^{7}$ or $10^{3}$ CFU of UTI89, or we treated mice infected with $10^{7} \mathrm{CFU}$ of UTI89 with antibiotics 1 day PI. We challenged all resolved mice with $10^{7} \mathrm{CFU}$ of UTI89 28 days post-primary infection and analyzed bladder resident $\mathrm{T}$ cell populations by flow cytometry. Defining these cells as $\mathrm{CD}^{+}$, and using CD4, CD8, CD69 and/or CD103 expression, we observed a significant reduction in the number of CD4 $\mathrm{T}_{\mathrm{RM}}$ cells, $\mathrm{CD} 8 \mathrm{~T}_{\mathrm{RM}}$ cells, double negative (DN) $\mathrm{T}_{\mathrm{RM}}$ cells, and double positive (DP) $\mathrm{T}_{\mathrm{RM}}$ cells in mice infected with $10^{3} \mathrm{CFU}$ compared to mice infected with $10^{7} \mathrm{CFU}$ (Figure 6A) or in mice treated with antibiotics compared to control-treated mice (Figure 6B). Supporting that it was specifically bladder $T_{R M}$ cells that mediate memory, there were no differences in the number of $\mathrm{T}_{\mathrm{RM}}$ subsets in bladder draining lymph nodes in any of the tested conditions (Supplementary Figure 3). Thus, reducing antigen load or persistence negatively impacted only local $\mathrm{T}_{\mathrm{RM}} \mathrm{T}$ cell populations in the bladder, correlating with a negative impact on immune memory.

To formally demonstrate that $\mathrm{T}_{\mathrm{RM}}$ cells mediate protection against a second or recurrent UTI, we hypothesized that their elimination should abrogate immune memory. However, currently, there are no specific tools that target $T_{R M}$ cells without also impacting circulating $T$ cell populations. As an alternative approach, we chose to eliminate all $\mathrm{T}$ cells subsets except $\mathrm{T}_{\mathrm{RM}}$ cells. $\mathrm{T}_{\mathrm{RM}}$ cells can be protected from depleting antibodies when the antibodies are administered using certain doses or schedules (Davies et al., 2017; Galvez-Cancino et al., 2018; Gebhardt et al., 2011; Turner et al., 2018). We took advantage of this to create a scenario in which the only memory $\mathrm{T}$ cells present during a challenge infection would be the $\mathrm{T}_{\mathrm{RM}}$ cells in the bladder. Mice were infected with UPEC and a cohort of animals was sacrificed 24 hours PI infection. After resolution of infection, at day 28, mice received CD4 and CD8 depleting antibodies or their respective isotype controls. Mice were challenged 24 hours later with $10^{7} \mathrm{CFU}$ of UPEC. In T cell depleted but uninfected mice, we measured $\mathrm{T}$ cell depletion in the blood, draining lymph nodes, and bladder. CD3 T cells were significantly reduced in the circulation of antibody-treated mice compared to control isotype-treated animals, with the reduction coming from a near complete elimination of CD4, CD8 and DP T cells (Supplementary Figure 4A). As expected, DN T cells were unchanged, as this population would not be targeted by anti-CD4 or anti-CD8 
antibodies. Importantly, however, we also did not observe an increase in the DN $\mathrm{T}$ cell population, supporting that $\mathrm{CD} 4, \mathrm{CD} 8$, and DP T cells were truly eliminated from the blood and not just masked by CD4 and CD8 antibodies covering these epitopes. In bladder-draining lymph nodes of antibody-depleted mice, total CD4, CD8, and DP $\mathrm{T}_{\mathrm{CM}}$ and $\mathrm{T}_{\mathrm{EM}}$ cells, as well as CD4, CD8, and $\mathrm{DP} \mathrm{T}_{\mathrm{RM}}$ cells were significantly reduced to nearly zero, indicating depleting antibodies do access the lymph nodes and these cells were not available to infiltrate the bladder to mediate protection (Supplementary Figure 4B, 4C). Similar to the blood, the DN T cell subset did not decrease or increase, supporting that CD4, CD8, and DP T cell subsets were truly eliminated from the lymph nodes, as well. Importantly, analysis of the $T_{R M}$ populations in the bladder revealed that $\mathrm{T}_{\mathrm{RM}}$ cells were protected from antibody depletion and there was no reduction of CD4 $\mathrm{T}_{\mathrm{RM}}, \mathrm{CD} 8 \mathrm{~T}_{\mathrm{RM}}$, or DP $\mathrm{T}_{\mathrm{RM}}$ cell subsets in the bladders of mice that received CD4 and CD8 depleting antibodies compared to mice that were treated with isotype controls (Figure 6C). Thus, only $T_{R M}$ cells were present when we challenged these mice with a second UPEC infection.

Following challenge infection, isotype-treated mice had bacterial burdens that were significantly reduced compared to bacterial CFU measured after a primary infection, as expected. Remarkably, CD4 and CD8 antibody-treated mice were also protected from challenge infection, as shown by significantly reduced bacterial CFU in the bladder despite a near global T cell depletion, demonstrating that immune memory was intact in these animals (Figure 6D). In addition, the bacterial burden after challenge infection between the control and experimental groups was not significantly different. Thus, these results support that $\mathrm{T}_{\mathrm{RM}}$ cells, specifically in the bladder, rather than circulating memory $\mathrm{T}$ cells mediate protection against a second UTI. 
A

CD4 $\mathrm{T}_{\mathrm{RM}} \mathrm{T}$ cells

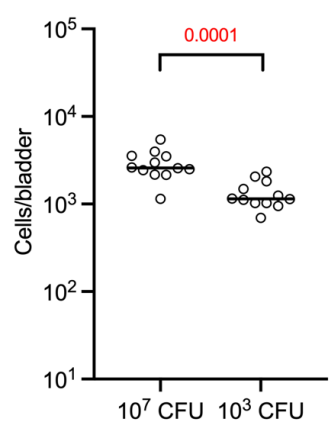

B

CD4 $\mathrm{T}_{\mathrm{RM}} \mathrm{T}$ cells

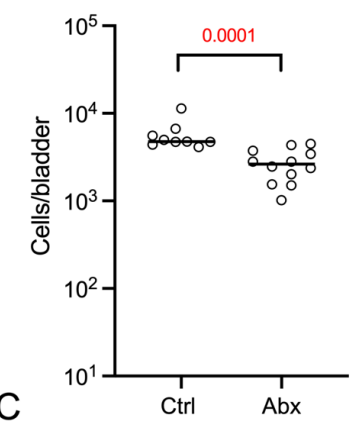

CD4 $\mathrm{T}_{\mathrm{RM}} \mathrm{T}$ cells

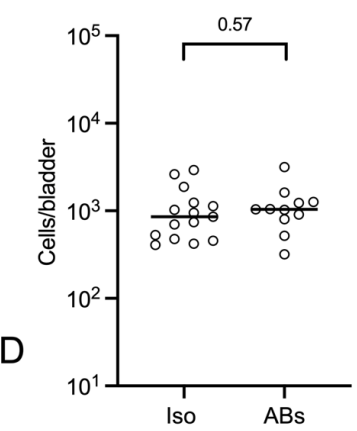

CD8 $\mathrm{T}_{\mathrm{RM}} \mathrm{T}$ cells

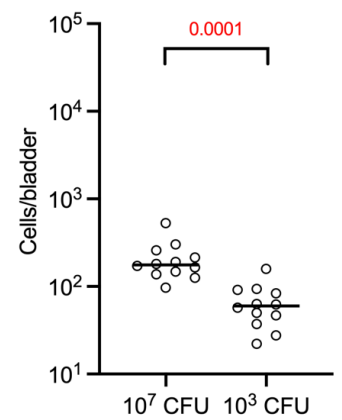

CD8 $\mathrm{T}_{\mathrm{RM}} \mathrm{T}$ cells

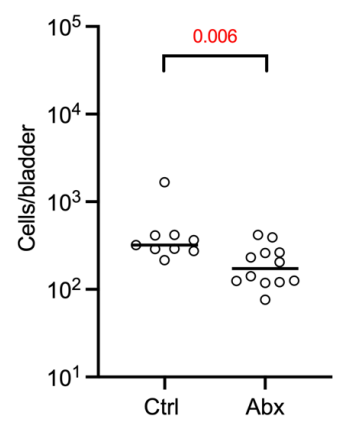

CD8 $\mathrm{T}_{\mathrm{RM}} \mathrm{T}^{\mathrm{c} \text { cells }}$

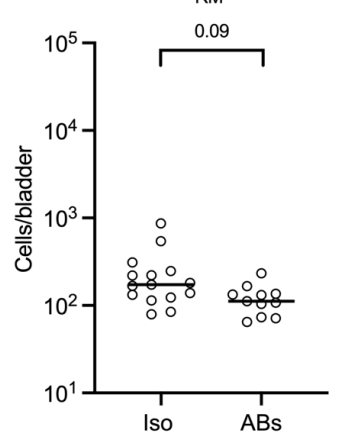

$\mathrm{DPT}_{\mathrm{RM}}{ }^{\mathrm{T}}$ cells

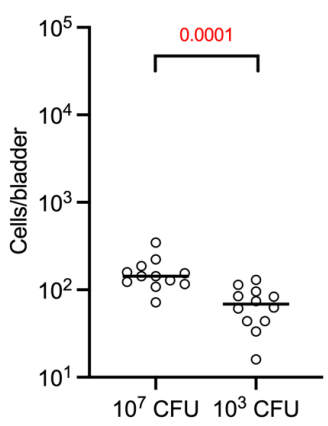

$\mathrm{DP}_{\mathrm{RM}}{ }^{\mathrm{T}}$ cells

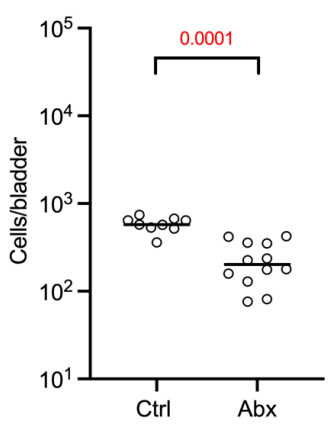

$\mathrm{DP}_{\mathrm{RM}} \mathrm{T}^{\mathrm{c} \text { cells }}$

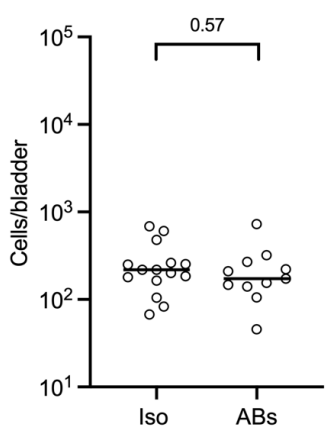

DN $\mathrm{T}_{\mathrm{RM}}{ }^{\mathrm{T}}$ cells

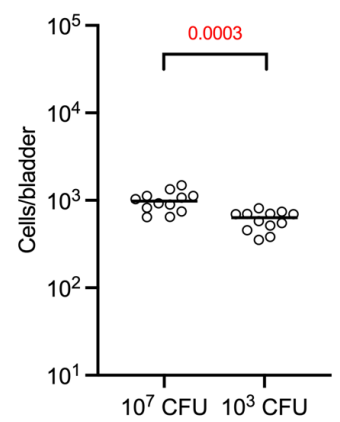

$\mathrm{DN} \mathrm{T}_{\mathrm{RM}} \mathrm{T}^{\mathrm{c}}$ cells
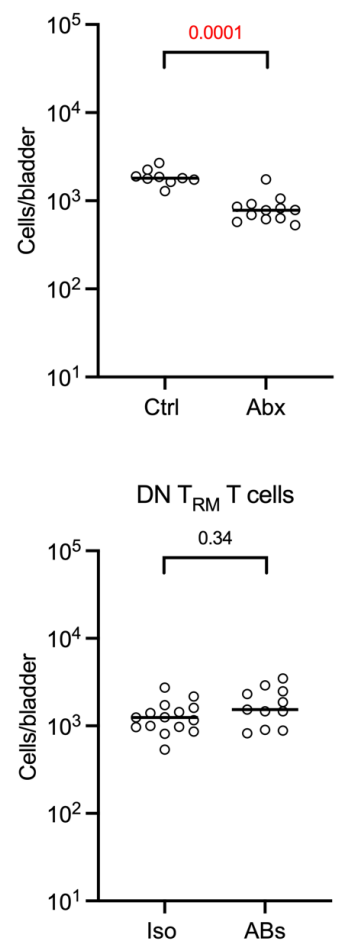

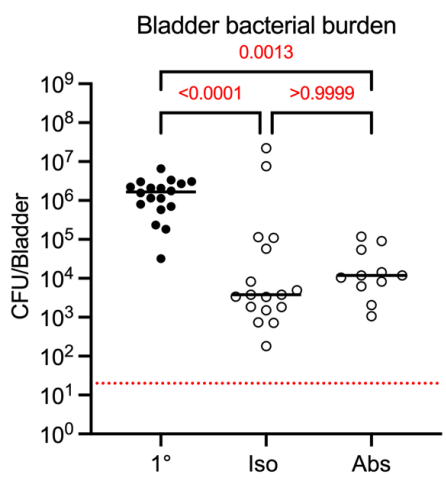

Figure 6: Tissue resident memory $T$ cells are sufficient to mediate protection against recurrent UTI. Graphs depict the total number of the specified $\mathrm{T}_{\mathrm{RM}}$ cell populations per bladder, identified by flow cytometry, after (A) six-week-old female C57BL/6 mice were instilled intravesically with $10^{7}$ or $10^{3} \mathrm{CFU}$ of UTI89, and following resolution, challenged with $10^{7} \mathrm{CFU}$ 
of UTI89 and sacrificed 24 hours post challenge infection or (B) mice were infected with $10^{7} \mathrm{CFU}$ of UTI89 and half of the animals were treated with antibiotics 24 hours PI. All resolved mice were challenged with $10^{7} \mathrm{CFU}$ of UTI89 28 days later and sacrificed 24 hours post-challenge infection. (C-D) Six-week-old female C57BL/6 mice were infected with $10^{7}$ CFU of UTI89 and treated with either anti-CD4 and anti-CD8 antibodies or their respective isotype controls at 28 days post-infection. Resolved mice were either sacrificed to assess depletion or challenged with $10^{7} \mathrm{CFU}$ of UTI89 and analyzed 24 hours post-challenge infection. Graphs depict (C) the total number of the specified $\mathrm{T}$ cell populations per bladder in unchallenged mice and (D) bladder bacterial burden. Data in $\mathbf{A}$ and $\mathbf{B}$ are pooled from 2 experiments, $n=3$ to 6 mice/group in each experiment. Data in $\mathbf{C}$ and $\mathbf{D}$ are pooled from 3 experiments, $\mathrm{n}=3$ to 6 mice/group in each experiment. Each dot is a mouse, lines are medians. In $\mathbf{D}$, dotted red lines depict the limit of detection of the assay. Significance was determined in A-C by nonparametric Mann-Whitney tests comparing cell numbers between each condition and all calculated $p$-values were corrected for multiple comparisons using the false discovery rate (FDR) method, and in D by KruskalWallis test comparing bladder bacterial burden 24 hours post primary infection to bacterial CFU 24 hours post challenge infection in isotype or depleting antibody-treated mice, or bacterial burden 24 hours post challenge in both conditions, with Dunn's post hoc test to correct for multiple comparisons. $p$-values $<0.05$ are in red.

\section{Discussion}

Overwhelmingly, studies of immunity to UTI focus on innate immunity, and despite how common recurrent UTI is, we have a poor understanding of how memory develops after an acute infection (Lacerda Mariano and Ingersoll, 2020). Supporting that humoral responses are important, UPECspecific antibody production is observed in children with pyelonephritis (Jodal et al., 1974) and, many years ago, antibodies were proposed as a biomarker of human pyelonephritis (Percival et al., 1964). Thus, it was surprising to rule out a role for B cells in our model of recurrent UTI. Notably, however, in a similar mouse UTI model, antibodies to UPEC arise only when bacteria colonize both the bladder and kidneys (Chan et al., 2013). We used C57BL/6 mice in our studies, and given that this background has a very low incidence of vesicoureteral reflux and kidney colonization (Murawski et al., 2010), and that antibodies are present specifically in cases of human pyelonephritis, our findings support that B cells are likely dispensable for memory to cystitis. This has potential consequences for future vaccines or other immunomodulatory strategies for recurrent UTI. Indeed, it may be that targeting the bladder to promote antibody production will not provide efficacious protection against cystitis, and may explain why vaccination strategies tested so far has not been successful.

Immune memory to UTI develops, but it is not sterilizing (Mora-Bau et al., 2015). Inadequate or inefficient memory responses likely play a role in the frequency of recurrent UTI. Recently, a study showed that a type 2 immune biased response develops following UTI in mice, and this bias was proposed as a reason for why memory is not sterilizing ( $\mathrm{Wu}$ et al., 2020). While a Th2 biased response would be expected to favor tissue repair over strong cellular immunity, our data show that this is not the underlying mechanism of insufficient memory to UTI. Previously, we reported that female and male mice develop comparable memory responses after an initial UTI, although male mice do not develop a type 2-biased immune response (Zychlinsky Scharff et al., 2019). In trying to understand this paradox, we found through global immunophenotyping that the immune response is not specifically biased towards any single Th subset, but rather that a mixed Th1, Th2, and Th17 response develops, with a robust infiltration of regulatory $\mathrm{T}$ cells. While this mixed response was not previously appreciated, it is not entirely surprising, as in the first 24 hours of infection, UPEC induces extensive tissue damage, including robust inflammation and urothelial cell exfoliation, and will be both intracellular and 
extracellular (Anderson et al., 2003; Ingersoll et al., 2008; Justice et al., 2004; Mora-Bau et al., 2015; Mulvey et al., 1998; Zychlinsky Scharff et al., 2019), necessitating a Th2 response to mediate repair, regulatory $\mathrm{T}$ cells to control effector cell activation, Th1-polarized $\mathrm{T}$ cells to eliminate intracellular pathogens and a Th17 response to target mucosal and extracellular pathogens concomitantly (Gieseck et al., 2018; Kaiko et al., 2008; Shevyrev and Tereshchenko, 2019; Vignali et al., 2008; Zhu et al., 2010). Indeed, this mixed response reflects the complexity of the host-pathogen interaction and immune response to UTI, as well as the fine equilibrium that must be established between resolution of infection and maintenance of bladder integrity.

Adding to our understanding of memory to UTI, the quantity and persistence of bacteria is a key parameter in the development of an adaptive immune response, and a minimum exposure of greater than 24 hours is needed for the development of adaptive immunity after a primary UTI. While additional studies are necessary to determine the mechanisms underlying this result, it may be that the rapid availability of antibiotics to individuals with a UTI actually places them at risk for recurrent infections by impeding memory responses. Determining whether delaying antibiotic treatment improves the memory response is feasible and may ultimately decrease the incidence of recurrence. Treatments that ameliorate symptoms but do not eliminate bacteria themselves, followed by delayed antibiotic therapy in those not at risk for pyelonephritis, may be a better therapeutic approach for lasting memory. Supporting this idea, while nonsteroidal anti-inflammatory drugs (NSAIDs) administered in place of antibiotics are not superior to antibiotic treatment (Gagyor et al., 2015; Kronenberg et al., 2017; Vik et al., 2018), a meta-analysis of 962 patients comparing antibiotic treatment to placebo for uncomplicated cystitis did not find a difference in the development of pyelonephritis (Falagas et al., 2009). This suggests that delaying antibiotics may not put individuals at greater risk for progression to pyelonephritis. Further supporting our alternative treatment proposal, NSAID-treated individuals had a significant reduction in the number of recurrent UTI in their first month post-treatment compared to those treated with antibiotics (Bleidorn et al., 2016). Thus, it would be of great value to test whether briefly delaying antibiotic treatment promotes a better memory response and a reduction in recurrent UTI in humans, which would, in turn, reduce reliance on antibiotics for this infection.

We previously reported that macrophage depletion before a primary or a challenge infection improves bacterial clearance during the challenge infection (Lacerda Mariano et al., 2020; Mora-Bau et al., 2015). This phenotype is T cell-dependent, and macrophage depletion specifically before the second UTI leads to an increase in Th1-biased immune cell infiltration (Lacerda Mariano et al., 2020; Mora-Bau et al., 2015). Thus, when we observed that memory was negatively impacted by decreasing the inoculum or administering antibiotics, we expected a change in the $\mathrm{T}$ cell polarization bias. We were surprised to observe changes only in $\mathrm{T}_{\mathrm{RM}}$ cell populations, which suggests to us that resident macrophages directly influence bladder resident $\mathrm{T}$ cell development or maintenance, potentially as a mechanism to maintain bladder integrity. As in other tissues, bladder resident macrophages likely modulate the microenvironment, which shapes the local $\mathrm{T}_{\mathrm{RM}}$ cell response. For instance, lung resident macrophages limit the development of influenza-specific CD8 $\mathrm{T}_{\mathrm{RM}}$ cells (Goplen et al., 2019). In Yersinia pseudotuberculosis infection, type I IFN and IL-12 in the intestinal microenvironment is key for the differentiation and persistence of $\mathrm{T}_{\mathrm{RM}}$ cells and depletion of CCR2 ${ }^{+}$IL-12-producing cells, including macrophages or monocytes, impedes $T_{\text {RM }}$ cell differentiation (Bergsbaken et al., 2017). Deciphering the mechanisms by which macrophages control local $\mathrm{T}$ cell responses in the bladder will be important to design efficacious immunomodulatory approaches.

The discovery of $\mathrm{T}_{\mathrm{RM}}$ cells localized in non-lymphoid tissues, which are anatomically well positioned to detect and respond to a second infection faster than $\mathrm{T}_{\mathrm{CM}}$ or $\mathrm{T}_{\mathrm{EM}}$ cells, has driven development of 
vaccine strategies to promote their differentiation. UTI needs new therapeutic approaches to combat the inevitable global spread of multidrug resistant bacteria. Vaccination strategies promoting the differentiation of bladder $\mathrm{T}_{\mathrm{RM}}$ cells would likely be of great benefit for patients suffering from recurrent UTI and would have a positive economic impact by reducing the cost of medical care. The failure of previous vaccine strategies for UTI may be because the correct vaccination strategy to promote the differentiation of $T_{R M}$ cells has not been identified. For example, a BCG mucosal vaccination better protects mice against tuberculosis compared to a subcutaneous vaccination, and adoptive transfer of $\mathrm{T}_{\mathrm{RM}}$ cells from vaccinated mice protects naïve animals from disease (Perdomo et al., 2016) and a mucosal vaccine approach provides superior protection against coronavirus infections compared to a subcutaneous route (Zhao et al., 2016). In addition to the route of vaccination, the type of vaccine used is also a key parameter. Indeed, an attenuated influenza vaccine promotes $T_{R M}$ cell generation in the lung, inducing long term protection, whereas an inactivated vaccine does not, despite intranasal delivery (Zens et al., 2016). Intranasal immunization with Chlamydia trachomatis promotes uterine mucosa protection and oral or gastrointestinal vaccination with Chlamydia muridarum protects the genital tract from infection (Stary et al., 2015; Wang et al., 2018). These observations will likely inform vaccine strategies for UTI and suggest that the bladder mucosa does not need to be directly targeted.

In sum, we demonstrated that bladder $\mathrm{T}_{\mathrm{RM}}$ cells mediate memory to UTI, and can do so in the absence of circulating or lymph node-resident $\mathrm{T}$ cells. Thus, we uncovered a specific, targetable population for development of new therapeutic approaches for this common infection plagued by antibiotic resistance. These findings greatly improve our understanding of adaptive immunity to UTI and provide valuable information for the design and development of much needed new non-antibiotic-based therapies.

\section{Materials and methods}

\section{Study design}

This study was conducted using a preclinical mouse model in controlled laboratory experiments to investigate adaptive immunity UTI. Our objective was to determine how an adaptive immune response develops after a UTI. Mice were assigned to groups by random partition into cages. In all experiments, a minimum of 2 and a maximum of 7 mice made up an experimental group and all experiments were repeated 2 to 5 times. Data from all repetitions were pooled before any statistical analysis. As determined a priori, all animals with abnormal kidneys (atrophied, enlarged, and/or white in color) at the time of sacrifice were excluded from all analyses, as we have observed that abnormal kidneys correlate with the inability to resolve infection. Animals with a recurrent or unresolved UTI, defined as having persistent bacteria in the urine up to 1 day prior to challenge infection, were also excluded. End points were determined before the start of experiments and researchers were not blinded to experimental groups.

\section{Ethics Statement}

Animal experiments were conducted in accordance with approval of protocol number 2012-0024 and 2016-0010 by the Comité d'éthique en expérimentation animale Paris Centre et Sud and the Comités d'Ethique pour l'Expérimentation Animale Institut Pasteur (the ethics committee for animal experimentation), in application of the European Directive 2010/63 EU. In all experiments, mice were anesthetized by intraperitoneal injection of $100 \mathrm{mg} / \mathrm{kg}$ ketamine and $5 \mathrm{mg} / \mathrm{kg}$ xylazine and sacrificed by carbon dioxide inhalation.

\section{Mice}

Female mice between the ages of 6 and 8 weeks were used in this study. Female C57BL/6J mice were obtained from Charles River Laboratories France. $\mu \mathrm{MT}^{--}$mice were bred in house at Institut Pasteur, Paris, and were a kind gift from Claude Leclerc. 


\section{UTI and determination of bacterial burden}

Female mice were anesthetized as described above, catheterized transurethrally, and infected with $1 \times 10^{7}, 1 \times 10^{5}$ or $1 \times 10^{3}$ colony forming units of UTI89-GFP-amp ${ }^{\mathrm{R}}$ or UTI89-RFP-kan ${ }^{\mathrm{R}}$ in $50 \mu \mathrm{L}$ PBS as previously described (Mora-Bau et al., 2015). UTI89-GFP-amp ${ }^{\mathrm{R}}$ and UTI89-RFP-kan ${ }^{\mathrm{R}}$ infect with equal efficiency and were used interchangeably (Mora-Bau et al., 2015). To detect cells by flow cytometry, only the nonfluorescent parental UTI89 strain was used.

Infection was monitored by detection of bacterial growth from urine samples collected twice per week. $2 \mu \mathrm{L}$ of urine were diluted directly into $8 \mu \mathrm{L}$ PBS spotted on agar plates containing antibiotics as appropriate (kanamycin $(50 \mu \mathrm{g} / \mathrm{ml})$ or ampicillin $(100 \mu \mathrm{g} / \mathrm{ml})$ ). The presence of any bacterial growth was counted as positive for infection. The limit of detection (LOD) for this assay is 500 bacteria per $\mathrm{mL}$ of urine. Mice were sacrificed at indicated time points, bladders homogenized in sterile PBS, serially diluted, and plated on LB agar plates with antibiotics, as appropriate, to determine CFU. The LOD for CFU in the bladder is $20 \mathrm{CFU}$ per bladder and is indicated by a dotted line in graphs. All sterile organs are reported at the LOD.

\section{Flow cytometry of bladder tissue, draining lymph nodes and blood}

Samples were acquired on a BD LSRFortessa using DIVA software (v8.0.1), and data were analyzed by FlowJo (Treestar) software. Bladder and blood analysis was performed as described previously (Lacerda Mariano et al., 2020; Mora-Bau et al., 2015; Zychlinsky Scharff et al., 2017). Briefly, bladders were dissected, cut into small pieces, and digested using Liberase $(0.34 \mathrm{U} / \mathrm{ml})$ in phosphate-buffered saline (PBS) at $37^{\circ} \mathrm{C}$ for 1 hour with robust manual agitation every 15 min. Digestion was stopped by adding FACS buffer (PBS supplemented with $2 \%$ fetal bovine serum and $0.2 \mu \mathrm{M}$ EDTA). Single cell suspensions were washed and resuspended in brilliant stain buffer (BD) with anti-mouse CD16/CD32 to block Fc receptors. Antibody mixes (Supplemental Table 1) in brilliant stain buffer were added directly to the samples after 10 minutes. Total cell counts were determined by addition of AccuCheck counting beads to a known volume of sample after staining, just before cytometer acquisition. To determine cell populations in the circulation, whole blood was incubated with BD PharmLyse and stained with antibodies (Supplemental Table 1). Total cell counts per $\mu \mathrm{L}$ of blood were determined by the addition of AccuCheck counting beads to $10 \mu \mathrm{l}$ of whole blood in 1-step BD Fix/Lyse Solution. Draining lymph nodes were disrupted with $27 \mathrm{G}$ needles and passed through $70 \mu \mathrm{m}$ filters (Miltenyi). Single cell suspensions were washed and resuspended in brilliant stain buffer with anti-mouse CD16/CD32 to block Fc receptors and subsequently stained as above for bladders. Total cell counts were determined as they were for the bladder. Memory $\mathrm{T}$ cell staining was performed at $37^{\circ} \mathrm{C}$ for 30 minutes to enhance CCR7 staining (Berhanu et al., 2003).

For intracellular staining, single cell suspensions were resuspended in $1 \mathrm{ml}$ of Golgi Stop protein transport inhibitor diluted 1:1500 in RPMI with 10\% FBS, 1\% sodium pyruvate, 1X HEPES, 1X nonessential amino acid, $1 \%$ penicillin-streptomycin, phorbol 12 -myristate 13 -acetate $(50 \mathrm{ng} / \mathrm{ml})$, and ionomycin $(1 \mu \mathrm{g} / \mathrm{ml})$, and incubated for 4 hours at $37^{\circ} \mathrm{C}$. Samples were washed once with FACS buffer and Fc receptors blocked with anti-mouse CD16/CD32. Samples were stained with antibodies listed in Supplemental Table 1 against surface markers and fixed and permeabilized with $1 \mathrm{X}$ fixation and permeabilization buffer and incubated at $4^{\circ} \mathrm{C}$ for 40 to $50 \mathrm{~min}$ protected from light. After incubation, samples were washed two times with $1 \mathrm{X}$ permeabilization and wash buffer from the transcription factor buffer kit (BD Biosciences) and stained with antibodies against IFN- $\gamma$, IL-17, IL-4, and the transcription factors ROR $\gamma \mathrm{T}$, Gata-3, T-bet, and FoxP3 (Supplemental Table 1), diluted in 1X permeabilization and wash buffer at $4^{\circ} \mathrm{C}$ for 40 to $50 \mathrm{~min}$ protected from light. Finally, samples were washed two times with 
$1 \mathrm{X}$ permeabilization and wash buffer and resuspended in FACS buffer. Total cell counts were determined by addition of counting beads to a known volume of sample after staining, just before cytometer acquisition.

\section{Immune cell depletion}

To deplete T cells, $100 \mu \mathrm{g}$ of CD4 and/or $100 \mu \mathrm{g}$ of CD8 (clone GK1.5, clone YTS 169.4, respectively, Bio X Cell) depleting antibodies were injected intraperitoneally in $100 \mu l$ sterile PBS per mouse 3 days before primary infection, or 24 hours before challenge infection. $100 \mu \mathrm{g}$ or $200 \mu \mathrm{g}$ of the isotype control (clone LTF-2, Bio X Cell) were injected intraperitoneally in $100 \mu \mathrm{l}$ of sterile PBS per mouse at the same time in control groups. Antibody injections given before the primary infection were repeated 7 days after the first injection, i.e., day 4 PI.

\section{Statistical analysis}

Statistical analysis was performed in GraphPad Prism 9 (GraphPad, USA) for Mac OS X applying the nonparametric Mann-Whitney test for unpaired data in the case of two group comparisons. To correct for comparisons made within an entire analysis or experiment, calculated $p$-values were corrected for multiple testing with the false discovery rate (FDR) method to determine the FDR-adjusted $p$-value. In the case that more than two groups were being compared, Kruskal-Wallis tests were performed, with Dunn's post hoc test to correct for multiple comparisons. All adjusted $p$-values are shown in the figures.

\section{Acknowledgments}

We are thankful for insightful discussion with Dr. Elizabeth Wohlfort. Funding: LLM was part of the Pasteur-Paris University (PPU) International PhD Program, which received funding from the European Union's Horizon 2020 research and innovation program under the Marie Sklodowska-Curie grant agreement no. 665807 and from the Labex Milieu Intérieur (ANR-10-LABX-69-01). MAI was supported by funding from the Agence Nationale de la Recherché (French National Research Agency) ANR-17-CE17-0014 and ANR-19-CE15-0015.

\section{Author contributions}

Conceptualization: MR, LLM and MAI; Methodology: MR, LLM, TC, MAI; Investigation and data analysis: MR, TC, MAI; Writing - Original Draft: MR and MAI; Writing - Review \& Editing: MR, LLM, TC, MAI; Funding Acquisition: MAI; Supervision: MAI.

\section{Competing interests}

The authors declare no competing interests.

\section{Data and materials availability}

Further information and requests for resources and reagents should be directed to and will be fulfilled by Molly A. Ingersoll (molly.ingersoll@pasteur.fr, molly.ingersoll@inserm.fr).

\section{References}

Akkaya, M., Kwak, K., and Pierce, S.K. (2020). B cell memory: building two walls of protection against pathogens. Nat Rev Immunol 20, 229-238.

Alteri, C.J., Hagan, E.C., Sivick, K.E., Smith, S.N., and Mobley, H.L. (2009). Mucosal immunization with iron receptor antigens protects against urinary tract infection. PLoS Pathog 5, e1000586.

Anderson, G.G., Palermo, J.J., Schilling, J.D., Roth, R., Heuser, J., and Hultgren, S.J. (2003). Intracellular bacterial biofilm-like pods in urinary tract infections. Science 301, 105-107. 
Baras, A.S., Drake, C., Liu, J.J., Gandhi, N., Kates, M., Hoque, M.O., Meeker, A., Hahn, N., Taube, J.M., Schoenberg, M.P., et al. (2016). The ratio of CD8 to Treg tumor-infiltrating lymphocytes is associated with response to cisplatin-based neoadjuvant chemotherapy in patients with muscle invasive urothelial carcinoma of the bladder. Oncoimmunology 5, e1134412.

Bergsbaken, T., Bevan, M.J., and Fink, P.J. (2017). Local Inflammatory Cues Regulate Differentiation and Persistence of CD8(+) Tissue-Resident Memory T Cells. Cell Rep 19, 114-124.

Berhanu, D., Mortari, F., De Rosa, S.C., and Roederer, M. (2003). Optimized lymphocyte isolation methods for analysis of chemokine receptor expression. J Immunol Methods 279, 199-207.

Billips, B.K., Yaggie, R.E., Cashy, J.P., Schaeffer, A.J., and Klumpp, D.J. (2009). A live-attenuated vaccine for the treatment of urinary tract infection by uropathogenic Escherichia coli. J Infect Dis 200, 263-272.

Bleidorn, J., Hummers-Pradier, E., Schmiemann, G., Wiese, B., and Gagyor, I. (2016). Recurrent urinary tract infections and complications after symptomatic versus antibiotic treatment: follow-up of a randomised controlled trial. Ger Med Sci 14, Doc01.

Chan, C.Y., St John, A.L., and Abraham, S.N. (2013). Mast cell interleukin-10 drives localized tolerance in chronic bladder infection. Immunity 38, 349-359.

Chromek, M., and Brauner, A. (2007). Urinary Tract Infection. Why Do Some Children Get Complications, While Others Dont? Current Pediatric Reviews 3, 35-44.

Davies, B., Prier, J.E., Jones, C.M., Gebhardt, T., Carbone, F.R., and Mackay, L.K. (2017). Cutting Edge: Tissue-Resident Memory T Cells Generated by Multiple Immunizations or Localized Deposition Provide Enhanced Immunity. J Immunol 198, 2233-2237.

De Nisco, N.J., Neugent, M., Mull, J., Chen, L., Kuprasertkul, A., de Souza Santos, M., Palmer, K.L., Zimmern, P., and Orth, K. (2019). Direct Detection of Tissue-Resident Bacteria and Chronic Inflammation in the Bladder Wall of Postmenopausal Women with Recurrent Urinary Tract Infection. J Mol Biol 431, 4368-4379.

Dielubanza, E.J., and Schaeffer, A.J. (2011). Urinary tract infections in women. Med Clin North Am 95, 27-41.

Falagas, M.E., Kotsantis, I.K., Vouloumanou, E.K., and Rafailidis, P.I. (2009). Antibiotics versus placebo in the treatment of women with uncomplicated cystitis: a meta-analysis of randomized controlled trials. J Infect 58, 91-102.

Falivene, J., Ghiglione, Y., Laufer, N., Socias, M.E., Holgado, M.P., Ruiz, M.J., Maeto, C., Figueroa, M.I., Giavedoni, L.D., Cahn, P., et al. (2015). Th17 and Th17/Treg ratio at early HIV infection associate with protective HIV-specific CD8(+) T-cell responses and disease progression. Sci Rep 5, 11511.

Foxman, B. (2002). Epidemiology of urinary tract infections: incidence, morbidity, and economic costs. Am J Med 113 Suppl 1A, 5S-13S.

Gagyor, I., Bleidorn, J., Kochen, M.M., Schmiemann, G., Wegscheider, K., and Hummers-Pradier, E. (2015). Ibuprofen versus fosfomycin for uncomplicated urinary tract infection in women: randomised controlled trial. BMJ 351, h6544.

Galvez-Cancino, F., Lopez, E., Menares, E., Diaz, X., Flores, C., Caceres, P., Hidalgo, S., Chovar, O., Alcantara-Hernandez, M., Borgna, V., et al. (2018). Vaccination-induced skin-resident memory CD8(+) $\mathrm{T}$ cells mediate strong protection against cutaneous melanoma. Oncoimmunology 7, e1442163. 
Gebhardt, T., Wakim, L.M., Eidsmo, L., Reading, P.C., Heath, W.R., and Carbone, F.R. (2009). Memory $\mathrm{T}$ cells in nonlymphoid tissue that provide enhanced local immunity during infection with herpes simplex virus. Nat Immunol 10, 524-530.

Gebhardt, T., Whitney, P.G., Zaid, A., Mackay, L.K., Brooks, A.G., Heath, W.R., Carbone, F.R., and Mueller, S.N. (2011). Different patterns of peripheral migration by memory CD4+ and CD8+ T cells. Nature 477, 216-219.

Gieseck, R.L., 3rd, Wilson, M.S., and Wynn, T.A. (2018). Type 2 immunity in tissue repair and fibrosis. Nat Rev Immunol 18, 62-76.

Goplen, N.P., Huang, S., Zhu, B., Cheon, I.S., Son, Y.M., Wang, Z., Li, C., Dai, Q., Jiang, L., and Sun, J. (2019). Tissue-Resident Macrophages Limit Pulmonary CD8 Resident Memory T Cell Establishment. Front Immunol 10, 2332.

Hoepelman, A.I., van Buren, M., van den Broek, J., and Borleffs, J.C. (1992). Bacteriuria in men infected with HIV-1 is related to their immune status (CD4+ cell count). AIDS 6, 179-184.

Hooton, T.M., Scholes, D., Hughes, J.P., Winter, C., Roberts, P.L., Stapleton, A.E., Stergachis, A., and Stamm, W.E. (1996). A prospective study of risk factors for symptomatic urinary tract infection in young women. N Engl J Med 335, 468-474.

Iijima, N., and Iwasaki, A. (2014). T cell memory. A local macrophage chemokine network sustains protective tissue-resident memory CD4 T cells. Science 346, 93-98.

Ikaheimo, R., Siitonen, A., Heiskanen, T., Karkkainen, U., Kuosmanen, P., Lipponen, P., and Makela, P.H. (1996). Recurrence of urinary tract infection in a primary care setting: analysis of a 1-year followup of 179 women. Clin Infect Dis 22, 91-99.

Ingersoll, M.A., and Albert, M.L. (2013). From infection to immunotherapy: host immune responses to bacteria at the bladder mucosa. Mucosal immunology 6, 1041-1053.

Ingersoll, M.A., Kline, K.A., Nielsen, H.V., and Hultgren, S.J. (2008). G-CSF induction early in uropathogenic Escherichia coli infection of the urinary tract modulates host immunity. Cell Microbiol $10,2568-2578$.

Ji, L., Zhan, Y., Hua, F., Li, F., Zou, S., Wang, W., Song, D., Min, Z., Chen, H., and Cheng, Y. (2012). The ratio of Treg/Th17 cells correlates with the disease activity of primary immune thrombocytopenia. PLoS One 7, e50909.

Jiang, X., Clark, R.A., Liu, L., Wagers, A.J., Fuhlbrigge, R.C., and Kupper, T.S. (2012). Skin infection generates non-migratory memory CD8+ T(RM) cells providing global skin immunity. Nature 483, $227-$ 231.

Jodal, U., Ahlstedt, S., Carlsson, B., Hanson, L.A., Lindberg, U., and Sohl, A. (1974). Local antibodies in childhood urinary tract infection: a preliminary study. Int Arch Allergy Appl Immunol 47, 537-546.

Justice, S.S., Hung, C., Theriot, J.A., Fletcher, D.A., Anderson, G.G., Footer, M.J., and Hultgren, S.J. (2004). Differentiation and developmental pathways of uropathogenic Escherichia coli in urinary tract pathogenesis. Proc Natl Acad Sci U S A 101, 1333-1338.

Kaiko, G.E., Horvat, J.C., Beagley, K.W., and Hansbro, P.M. (2008). Immunological decision-making: how does the immune system decide to mount a helper T-cell response? Immunology 123, 326-338.

Kitamura, D., Roes, J., Kuhn, R., and Rajewsky, K. (1991). A B cell-deficient mouse by targeted disruption of the membrane exon of the immunoglobulin mu chain gene. Nature 350, 423-426. 
Klein, R.D., and Hultgren, S.J. (2020). Urinary tract infections: microbial pathogenesis, host-pathogen interactions and new treatment strategies. Nat Rev Microbiol 18, 211-226.

Kronenberg, A., Butikofer, L., Odutayo, A., Muhlemann, K., da Costa, B.R., Battaglia, M., Meli, D.N., Frey, P., Limacher, A., Reichenbach, S., and Juni, P. (2017). Symptomatic treatment of uncomplicated lower urinary tract infections in the ambulatory setting: randomised, double blind trial. BMJ 359, j4784.

Lacerda Mariano, L., and Ingersoll, M.A. (2020). The immune response to infection in the bladder. Nat Rev Urol 17, 439-458.

Lacerda Mariano, L., Rousseau, M., Varet, H., Legendre, R., Gentek, R., Saenz Coronilla, J., Bajenoff, M., Gomez Perdiguero, E., and Ingersoll, M.A. (2020). Functionally distinct resident macrophage subsets differentially shape responses to infection in the bladder. Sci Adv 6.

Langermann, S., Palaszynski, S., Barnhart, M., Auguste, G., Pinkner, J.S., Burlein, J., Barren, P., Koenig, S., Leath, S., Jones, C.H., and Hultgren, S.J. (1997). Prevention of mucosal Escherichia coli infection by FimH-adhesin-based systemic vaccination. Science 276, 607-611.

Lipsky, B.A. (1989). Urinary tract infections in men. Epidemiology, pathophysiology, diagnosis, and treatment. Ann Intern Med 110, 138-150.

Litwin, M.S., Saigal, C.S., and editors. (2007). Urologic Diseases in America. Washington. P.H.S. U.S. Department of Health and Human Services, National Institutes of Health, National Institute of Diabetes and Digestive and Kidney Diseases, ed. (D.C, U.S. Government Publishing Office).

Mazor-Dray, E., Levy, A., Schlaeffer, F., and Sheiner, E. (2009). Maternal urinary tract infection: is it independently associated with adverse pregnancy outcome? J Matern Fetal Neonatal Med 22, 124-128.

Mora-Bau, G., Platt, A.M., van Rooijen, N., Randolph, G.J., Albert, M.L., and Ingersoll, M.A. (2015). Macrophages Subvert Adaptive Immunity to Urinary Tract Infection. PLoS Pathog 11, e1005044.

Mueller, S.N., Gebhardt, T., Carbone, F.R., and Heath, W.R. (2013). Memory T cell subsets, migration patterns, and tissue residence. Annu Rev Immunol 31, 137-161.

Mulvey, M.A., Lopez-Boado, Y.S., Wilson, C.L., Roth, R., Parks, W.C., Heuser, J., and Hultgren, S.J. (1998). Induction and evasion of host defenses by type 1-piliated uropathogenic Escherichia coli. Science 282, 1494-1497.

Murawski, I.J., Maina, R.W., Malo, D., Guay-Woodford, L.M., Gros, P., Fujiwara, M., Morgan, K., and Gupta, I.R. (2010). The $\mathrm{C} 3 \mathrm{H} / \mathrm{HeJ}$ inbred mouse is a model of vesico-ureteric reflux with a susceptibility locus on chromosome 12. Kidney Int 78, 269-278.

Mysorekar, I.U., and Hultgren, S.J. (2006). Mechanisms of uropathogenic Escherichia coli persistence and eradication from the urinary tract. Proc Natl Acad Sci U S A 103, 14170-14175.

Percival, A., Birumfitt, W., and Delouvois, J. (1964). Serum-Antibody Levels as an Indication of Clinically Inapparent Pyelonephritis. Lancet 2, 1027-1033.

Perdomo, C., Zedler, U., Kuhl, A.A., Lozza, L., Saikali, P., Sander, L.E., Vogelzang, A., Kaufmann, S.H., and Kupz, A. (2016). Mucosal BCG Vaccination Induces Protective Lung-Resident Memory T Cell Populations against Tuberculosis. mBio 7.

Preston, C.C., Maurer, M.J., Oberg, A.L., Visscher, D.W., Kalli, K.R., Hartmann, L.C., Goode, E.L., and Knutson, K.L. (2013). The ratios of CD8+ T cells to CD4+CD25+ FOXP3+ and FOXP3- T cells correlate with poor clinical outcome in human serous ovarian cancer. PLoS One 8 , e80063. 
Romagnoli, P.A., Fu, H.H., Qiu, Z., Khairallah, C., Pham, Q.M., Puddington, L., Khanna, K.M., Lefrancois, L., and Sheridan, B.S. (2017). Differentiation of distinct long-lived memory CD4 T cells in intestinal tissues after oral Listeria monocytogenes infection. Mucosal Immunol 10, 520-530.

Ruben, F.L., Dearwater, S.R., Norden, C.W., Kuller, L.H., Gartner, K., Shalley, A., Warshafsky, G., Kelsey, S.F., O'Donnell, C., Means, E., and et al. (1995). Clinical infections in the noninstitutionalized geriatric age group: methods utilized and incidence of infections. The Pittsburgh Good Health Study. Am J Epidemiol 141, 145-157.

Schenkel, J.M., Fraser, K.A., Vezys, V., and Masopust, D. (2013). Sensing and alarm function of resident memory CD8(+) T cells. Nat Immunol 14, 509-513.

Shevyrev, D., and Tereshchenko, V. (2019). Treg Heterogeneity, Function, and Homeostasis. Front Immunol 10,3100.

Shin, H., and Iwasaki, A. (2012). A vaccine strategy that protects against genital herpes by establishing local memory T cells. Nature 491, 463-467.

Sivick, K.E., and Mobley, H.L. (2009). Waging War against Uropathogenic Escherichia coli: Winning Back the Urinary Tract. Infect Immun.

Spaulding, C.N., Klein, R.D., Ruer, S., Kau, A.L., Schreiber, H.L., Cusumano, Z.T., Dodson, K.W., Pinkner, J.S., Fremont, D.H., Janetka, J.W., et al. (2017). Selective depletion of uropathogenic E. coli from the gut by a FimH antagonist. Nature 546, 528-532.

Stary, G., Olive, A., Radovic-Moreno, A.F., Gondek, D., Alvarez, D., Basto, P.A., Perro, M., Vrbanac, V.D., Tager, A.M., Shi, J., et al. (2015). VACCINES. A mucosal vaccine against Chlamydia trachomatis generates two waves of protective memory T cells. Science 348 , aaa 8205 .

Svanborg-Eden, C., and Svennerholm, A.M. (1978). Secretory immunoglobulin A and G antibodies prevent adhesion of Escherichia coli to human urinary tract epithelial cells. Infect Immun 22, 790-797.

Teijaro, J.R., Turner, D., Pham, Q., Wherry, E.J., Lefrancois, L., and Farber, D.L. (2011). Cutting edge: Tissue-retentive lung memory CD4 T cells mediate optimal protection to respiratory virus infection. $\mathrm{J}$ Immunol 187, 5510-5514.

Thumbikat, P., Waltenbaugh, C., Schaeffer, A.J., and Klumpp, D.J. (2006). Antigen-specific responses accelerate bacterial clearance in the bladder. J Immunol 176, 3080-3086.

Turner, D.L., Goldklang, M., Cvetkovski, F., Paik, D., Trischler, J., Barahona, J., Cao, M., Dave, R., Tanna, N., D'Armiento, J.M., and Farber, D.L. (2018). Biased Generation and In Situ Activation of Lung Tissue-Resident Memory CD4 T Cells in the Pathogenesis of Allergic Asthma. J Immunol 200, 15611569.

Uehling, D.T., Hopkins, W.J., Balish, E., Xing, Y., and Heisey, D.M. (1997). Vaginal mucosal immunization for recurrent urinary tract infection: phase II clinical trial. J Urol 157, 2049-2052.

Uehling, D.T., Hopkins, W.J., Beierle, L.M., Kryger, J.V., and Heisey, D.M. (2001). Vaginal mucosal immunization for recurrent urinary tract infection: extended phase II clinical trial. J Infect Dis 183 Suppl $1, \mathrm{~S} 81-83$.

Uehling, D.T., Hopkins, W.J., Dahmer, L.A., and Balish, E. (1994). Phase I clinical trial of vaginal mucosal immunization for recurrent urinary tract infection. J Urol 152, 2308-2311.

Uehling, D.T., James, L.J., Hopkins, W.J., and Balish, E. (1991). Immunization against urinary tract infection with a multi-valent vaginal vaccine. J Urol 146, 223-226. 
Vignali, D.A., Collison, L.W., and Workman, C.J. (2008). How regulatory T cells work. Nat Rev Immunol 8, 523-532.

Vik, I., Bollestad, M., Grude, N., Baerheim, A., Damsgaard, E., Neumark, T., Bjerrum, L., Cordoba, G., Olsen, I.C., and Lindbaek, M. (2018). Ibuprofen versus pivmecillinam for uncomplicated urinary tract infection in women-A double-blind, randomized non-inferiority trial. PLoS Med 15, e1002569.

Wang, L., Zhu, C., Zhang, T., Tian, Q., Zhang, N., Morrison, S., Morrison, R., Xue, M., and Zhong, G. (2018). Nonpathogenic Colonization with Chlamydia in the Gastrointestinal Tract as Oral Vaccination for Inducing Transmucosal Protection. Infect Immun 86.

Wu, J., Hayes, B.W., Phoenix, C., Macias, G.S., Miao, Y., Choi, H.W., Hughes, F.M., Jr., Todd Purves, J., Lee Reinhardt, R., and Abraham, S.N. (2020). A highly polarized TH2 bladder response to infection promotes epithelial repair at the expense of preventing new infections. Nat Immunol 21, 671-683.

Xiao, B.G., and Link, H. (1997). Mucosal tolerance: a two-edged sword to prevent and treat autoimmune diseases. Clin Immunol Immunopathol 85, 119-128.

$\mathrm{Xu}, \mathrm{T}$., $\mathrm{Lu}, \mathrm{J}$. , and $\mathrm{An}, \mathrm{H}$. (2017). The relative change in regulatory $\mathrm{T}$ cells / T helper lymphocytes ratio as parameter for prediction of therapy efficacy in metastatic colorectal cancer patients. Oncotarget 8 , 109079-109093.

Yang, J., Chu, Y., Yang, X., Gao, D., Zhu, L., Yang, X., Wan, L., and Li, M. (2009). Th17 and natural Treg cell population dynamics in systemic lupus erythematosus. Arthritis Rheum 60, 1472-1483.

Yordanova, I.A., Cortes, A., Klotz, C., Kuhl, A.A., Heimesaat, M.M., Cantacessi, C., Hartmann, S., and Rausch, S. (2019). RORgammat $(+)$ Treg to Th17 ratios correlate with susceptibility to Giardia infection. Sci Rep 9, 20328.

Yoshida, T., Hachimura, S., and Kaminogawa, S. (1997). The oral administration of low-dose antigen induces activation followed by tolerization, while high-dose antigen induces tolerance without activation. Clin Immunol Immunopathol 82, 207-215.

Zens, K.D., Chen, J.K., and Farber, D.L. (2016). Vaccine-generated lung tissue-resident memory T cells provide heterosubtypic protection to influenza infection. JCI Insight 1.

Zhao, J., Zhao, J., Mangalam, A.K., Channappanavar, R., Fett, C., Meyerholz, D.K., Agnihothram, S., Baric, R.S., David, C.S., and Perlman, S. (2016). Airway Memory CD4(+) T Cells Mediate Protective Immunity against Emerging Respiratory Coronaviruses. Immunity 44, 1379-1391.

Zhu, J., Yamane, H., and Paul, W.E. (2010). Differentiation of effector CD4 T cell populations (*). Annu Rev Immunol 28, 445-489.

Zychlinsky Scharff, A., Albert, M.L., and Ingersoll, M.A. (2017). Urinary Tract Infection in a Small Animal Model: Transurethral Catheterization of Male and Female Mice. J Vis Exp.

Zychlinsky Scharff, A., Rousseau, M., Lacerda Mariano, L., Canton, T., Consiglio, C.R., Albert, M.L., Fontes, M., Duffy, D., and Ingersoll, M.A. (2019). Sex differences in IL-17 contribute to chronicity in male versus female urinary tract infection. JCI Insight 5. 
Supplementary Information for

\title{
Bladder tissue-resident memory $T$ cells are necessary and sufficient to mediate immunity to recurrent UTI
}

\author{
Matthieu Rousseau ${ }^{1}$, Livia Lacerda Mariano ${ }^{1}$, Tracy Canton ${ }^{1}$, Molly A Ingersoll ${ }^{1, *}$
}

${ }^{1}$ Mucosal Inflammation and Immunity, Department of Immunology, Institut Pasteur, 75015 Paris, France and Inserm U1223, Paris France 
T cell infiltration $24 \mathrm{~h}$ post $1^{\circ}$

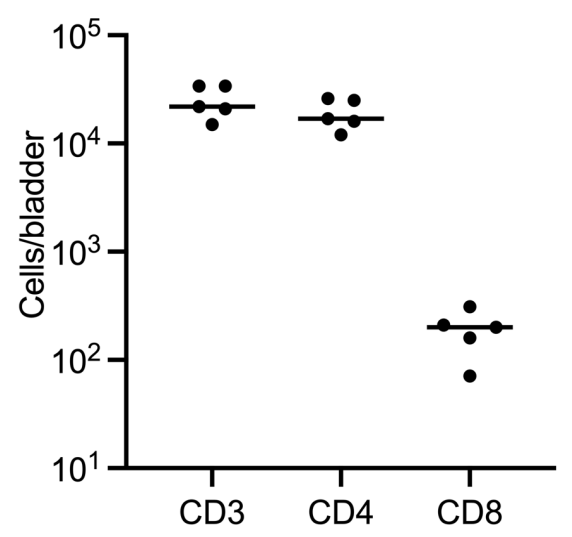

Supplementary Figure 1: CD8 T cells poorly infiltrate the bladder. Graph shows the total number of the specified $\mathrm{T}$ cell populations per bladder 24 hours post primary infection. A representative experiment from 3 experiments is presented. Each dot represents a mouse and lines are medians. 
A

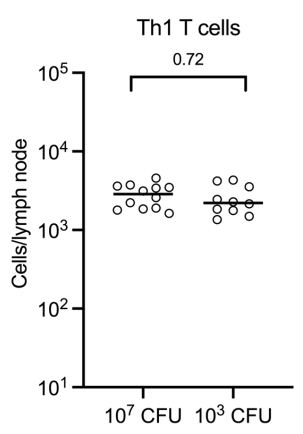

B

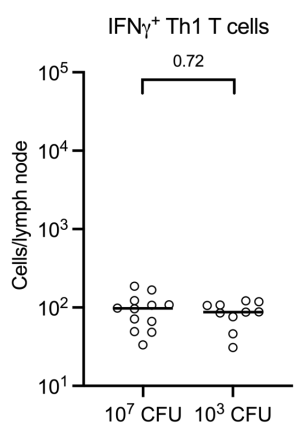

D

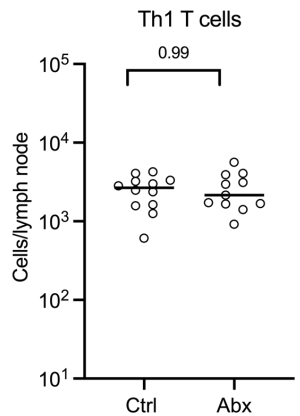

E

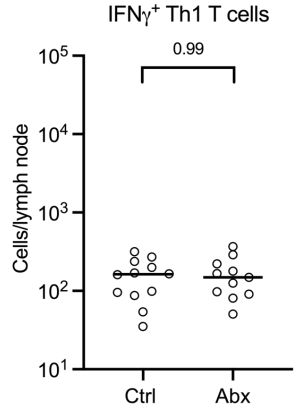

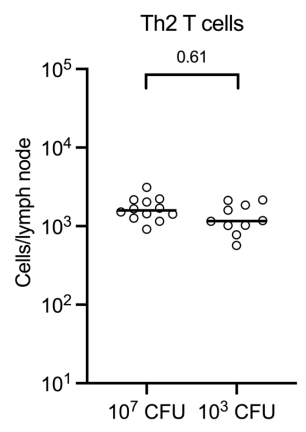

IL-17+ Th17 T cells
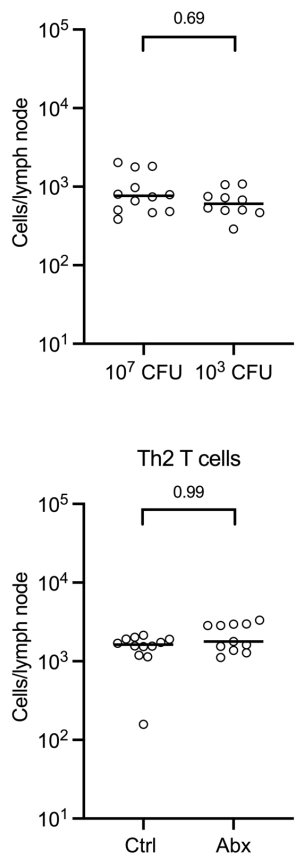

IL-17 $7^{+}$Th17 T cells

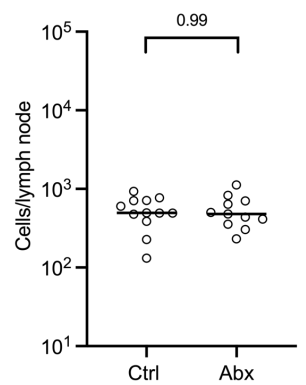

Th17 T cells

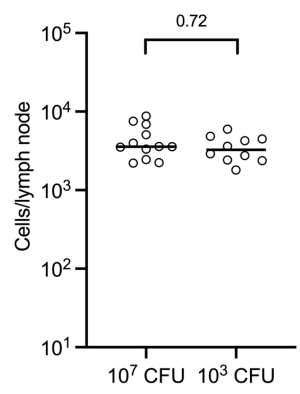

C

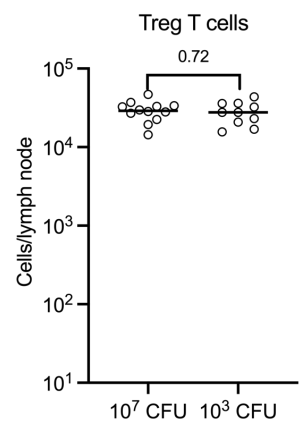

F

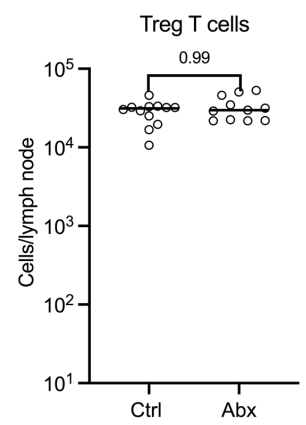

Supplementary Figure 2: Reduced antigen persistence does not change Th cell polarization in bladder-draining lymph nodes. Graphs show the total number of specified cell populations per bladder-draining lymph nodes (A-C) from mice presented in Figure 5 A-B. (D-F) shows draining lymph nodes of mice presented in Figure 5C-D analyzed by flow cytometry. Data are pooled from 2 experiments, $\mathrm{n}=4$ to 6 mice/group in each experiment (A-C), or $\mathrm{n}=5$ to 6 mice/group in each experiment (D-F). Each dot represents a mouse and lines are medians. Nonparametric Mann-Whitney tests comparing cell numbers between each condition were performed. $p$-values were corrected for multiple comparisons using the false discovery rate (FDR) method. Corrected $p$-values are shown. 
A
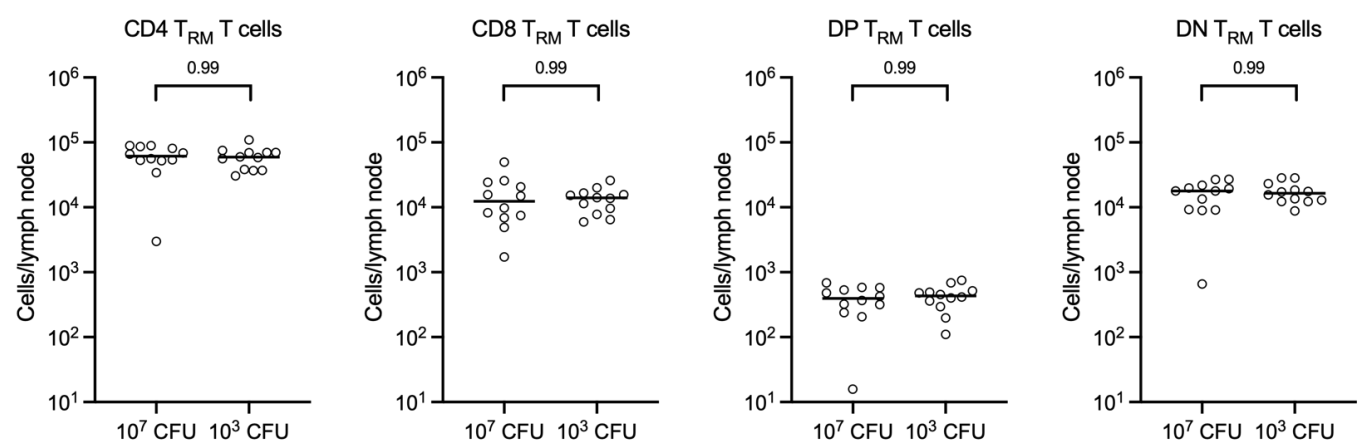

B
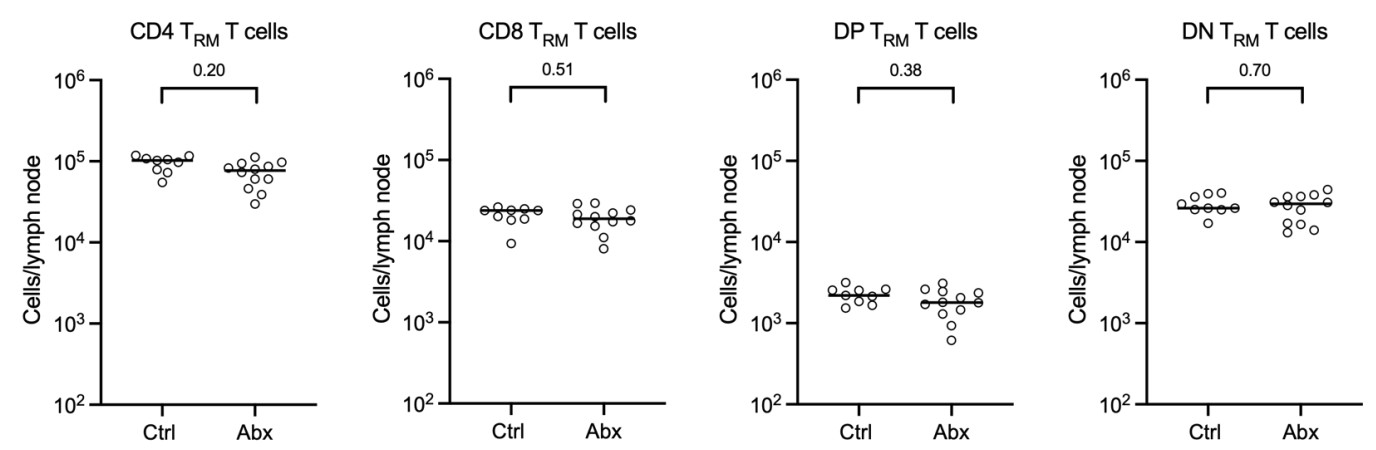

Supplementary Figure 3: Reduced antigen persistence does not impact bladder-draining lymph node tissue resident memory $\mathbf{T}$ cells. (A and B) Graphs show the total number of specified cell populations per bladder draining lymph nodes from mice (A) presented in Figure 6A and (B) presented in Figure 6B. Data are pooled from 2 experiments, $n=3$ to 6 mice/group in each experiment. Nonparametric Mann-Whitney tests comparing cell numbers between each condition were performed. $p$-values were corrected for multiple comparisons using the false discovery rate (FDR) method. Corrected $p$-values for each comparison are presented. 
A

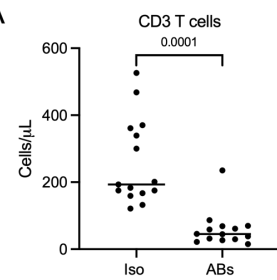

B

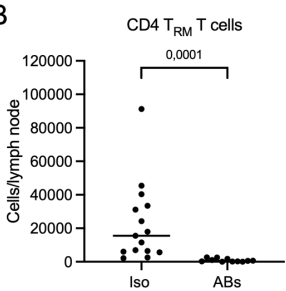

C
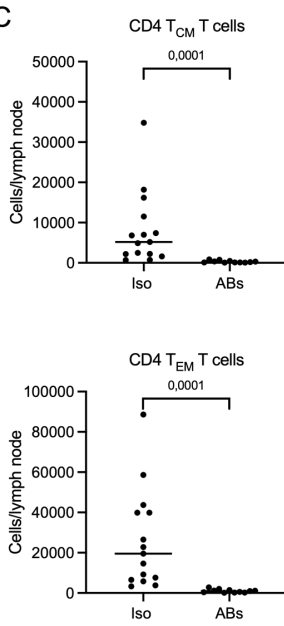
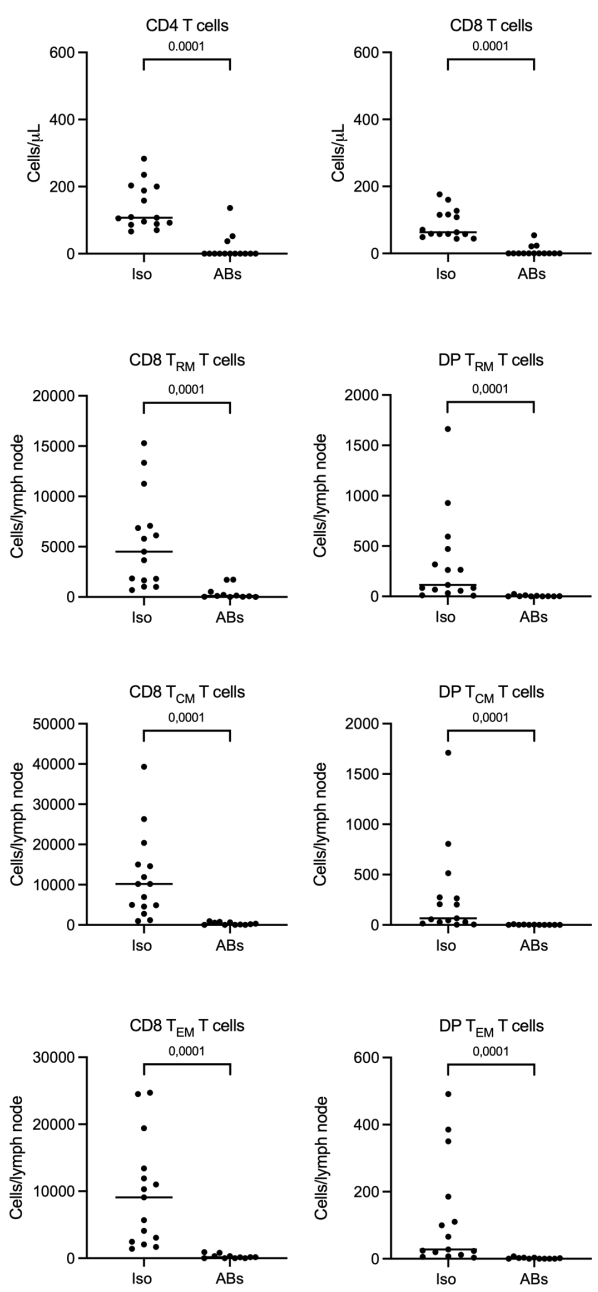
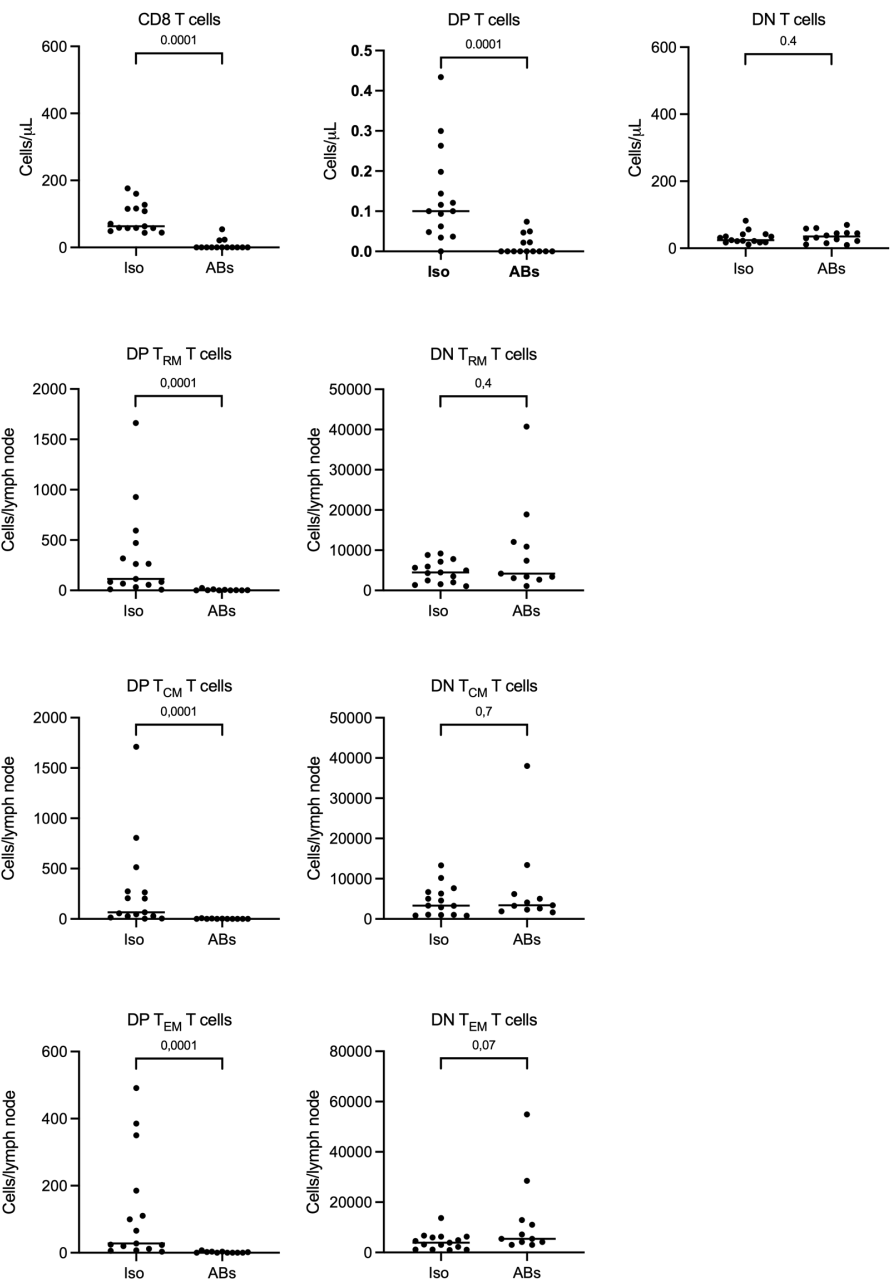

Supplementary Figure 4: CD4 and CD8 depletion efficiently eliminates T cells from the blood and memory $\mathbf{T}$ cells from the draining lymph nodes. (A, B, and $\mathbf{C}$ ) The blood and draining lymph nodes of mice presented in Figure 6C were collected and processed for flow cytometry. Graphs show the total number of specified cell populations in (A) blood and (B and $\mathbf{C})$ per bladder-draining lymph node. Data are pooled from 3 experiments, $n=3$ to 6 mice/group in each experiment. Each dot represents a mouse and lines are medians. Nonparametric Mann-Whitney tests comparing cell numbers between isotype and depletion conditions were performed. $p$-values were corrected for multiple comparisons using the false discovery rate (FDR) method. Corrected $p$-values for each comparison are presented. 